\title{
MINERÍA METALÍFERA, GUERRA Y ACUMULACIÓN POR DESPOSESIÓN: EL CASO DEL TUNGSTENO EN ARGENTINA DURANTE LOS CONFLICTOS INTERNACIONALES DEL SIGLO XX
}

\author{
Sebastián Gómez Lende \\ Investigador Independiente de CONICET \\ Instituto de Geografía, Historia y Ciencias Sociales, \\ Consejo Nacional de Investigaciones Científicas y Técnicas \\ Universidad Nacional del Centro de la Provincia de Buenos Aires \\ gomezlen@fch.unicen.edu.ar
}

\begin{abstract}
RESÚMEN
En las últimas décadas, las ciencias sociales han debatido exhaustivamente acerca de las severas consecuencias del avance de la minería metalífera en Argentina. Sin embargo, poco se sabe de los impactos generados por el sector durante las grandes guerras internacionales del Siglo XX, cuando nuestro país se convirtió en exportador de minerales críticos y estratégicos para la industria militar de los países en conflicto. Sobre la base de bibliografía especializada, estadísticas oficiales y reportes periodísticos, este artículo reconstruyó el desarrollo histórico de la minería del tungsteno durante la Primera y la Segunda Guerra Mundial y la Guerra de Corea para determinar si los ciclos de crecimiento resultantes de tales circunstancias implicaron para nuestro país mecanismos de acumulación por desposesión semejantes a los que actualmente prevalecen en el sector minero argentino. Los resultados muestran claramente que este modelo se basó en la privatización y apropiación imperial de recursos naturales, el fraude y la ilegalidad, las redistribuciones estatales y la tercerización de la fuerza de trabajo.
\end{abstract}

Palabras-clave: Minería metalífera. Extractivismo. Acumulación por desposesión. Primera y Segunda Guerra Mundial. Guerra de Corea. Argentina.

\section{METAL MINING, WAR AND ACCUMULATION BY DISPOSSESSION: THE CASE OF THE TUNGSTEN MINING IN ARGENTINA DURING THE OUTSIDE MILITARY CONFLICTS OF THE 20th CENTURY}

\begin{abstract}
During the last decades, social sciences have profusely discussed the serious consequences of the metal mining's progress in Argentina. Nevertheless, little is known about the impacts of this activity during the great wars of the 20th century, when Argentina became an exporter of critical, strategic minerals for the military industry of the countries at war. On the basis of specialized literature, official statistics and journalistic information, this paper reconstructs the historical development of tungsten mining in Argentina during the First and Second World War and Korean War in order to establish whether the boom cycles resulting from that circumstances led to mechanisms of accumulation by dispossession similar to those currently prevailing in the Argentinean mining sector. The findings clearly show that this pattern was based on the privatization and imperial grabbing of natural resources, fraud and illegality, state redistributions, and the workforce's super-exploitation and precariousness.
\end{abstract}

Keywords: Metal mining. Extractivism. Accumulation by dispossession. World War I and II. Korea War. Argentina.

\section{INTRODUCCIÓN}

Como es bien sabido, durante las últimas décadas el modelo extractivista y, más específicamente, la mega-minería metalífera, se han convertido en objeto de intensos debates en América Latina en general y en la Argentina en particular. No pocas ciencias sociales - encabezadas por la sociología, la ecología política y la geografía - han cuestionado los graves impactos sociales, económicos, políticos, territoriales y ambientales de la actividad. Dentro de esta vertiente crítica, algunos trabajos académicos se han esforzado por problematizar la cuestión en clave de acumulación por desposesión, tendiendo puentes entre las categorías de análisis propuestas por la teoría y las

$\begin{array}{lllll}\text { Caminhos de Geografia } \quad \text { Uberlândia-MG } & \text { v. 22, n. } 79 & \text { Fev/2021 } & \text { p. 18-38 } & \text { Página } 18\end{array}$


dinámicas expropiatorias del modelo minero argentino (MACHADO ARÁOZ, 2010; 2014; GÓMEZ LENDE, 2015; 2017).

No obstante, pocos abordajes y estudios de caso se han ocupado de realizar una tarea análoga para lo que podríamos denominar la minería "histórica" de la Argentina. En la bibliografía académica sobre la minería argentina existe cierto consenso de que en el pasado el sector metalífero se desarrolló de un modo bastante diferente al actual. Lejos de la abrumadora transnacionalización del sector y la febril extracción de oro, cobre, plata y litio en las faraónicas mega-explotaciones a cielo abierto que hoy día caracterizan a la actividad, durante la mayor parte del Siglo XX la minería metalífera argentina detentó una importancia bastante marginal que tuvo como rasgo distintivo la coexistencia de un puñado de grandes empresas extranjeras y estatales y una pléyade de firmas de capital nacional que, con excepciones puntuales, operaron a pequeña y mediana escala. A lo largo de gran parte de esa etapa, el sector estuvo liderado por una minería subterránea abocada a la extracción de metales básicos (hierro, plomo, zinc, estaño, manganeso) en gran medida orientados al mercado interno para satisfacer las necesidades del proceso de industrialización de la economía.

Sin perjuicio de lo anterior, es bastante menos conocido el hecho de que en esa misma época la Argentina exportaba minerales críticos o estratégicos (antimonio, berilo, columbio, tantalio, litio, wolframio, etc.) para abastecer a la industria militar de las potencias que participaron de las grandes guerras internacionales. Por diversas razones, el rubro más importante de este grupo fue el wolframio o tungsteno, un mineral cuya producción ha sido históricamente liderada por China, Birmania, Estados Unidos, Corea, Gran Bretaña, India, Portugal, España, Bolivia y la Argentina.

Presente en los depósitos de wolframita y scheelita de las provincias de San Luis, Córdoba y, en mucha menor medida, San Juan, La Rioja, Catamarca, Mendoza, Río Negro, Jujuy y Salta, el wolframio es un metal industrial de color negro o gris acero que desde 1847 viene siendo intensamente utilizado en el mundo para la producción de aleaciones a base de hierro. Su forma pura es el ácido tungstico, muy usado para la fabricación de aceros especiales, productos eléctricos y herramientas de corte ${ }^{1}$. Sin perjuicio de lo anterior, las singulares propiedades del wolframio -alta densidad y fortaleza, extremada dureza, difícil fusión y gran resistencia a la corrosión, el desgaste y el fuego ${ }^{2}-$ lo convierten en un material de uso obligado en la industria bélica para el blindaje de tanques de guerra y buques acorazados y la fabricación de cabezas de proyectiles de gran capacidad de penetración (DMyG, 1948; CARUANA DE LAS CAGIGAS y ROCKOFF, 2003).

Hasta el momento, las problemáticas relacionadas con el modelo de acumulación asociado a este tipo de minería han sido escasamente estudiadas desde el ámbito académico. Por un lado, existe un número apreciable de trabajos que desde una perspectiva geopolítica han analizado exhaustivamente los ciclos del wolframio en China, Corea, Portugal y España durante la Primera y la Segunda Guerra Mundial (CARMONA BADÍA, 2003; CARUANA DE LAS CAGIGAS y ROCKOFF, 2003; AVELÃS NUNES, 2010; CARUANA DE LAS CAGIGAS y GONZÁLEZ CALLEJA, 2014; THOMÀS, 2017), rozando muy tangencialmente -o directamente ignorando- el caso argentino. Por otra parte, los abordajes realizados a escala local se han limitado a un puñado de trabajos realizados por geólogos cuya naturaleza ha sido eminentemente descriptiva, adoleciendo de un enfoque teórico (CATALANO, 1984; 2004; ZOLEZZI, 2004a; 2004b). Pese a sus limitaciones, gracias a esas investigaciones se sabe que durante los grandes conflictos bélicos internacionales la minería del wolframio en Argentina suscitó intensos conflictos políticos, económicos e institucionales debido a la fuerte dependencia de los mercados externos, los altos niveles de extranjerización y cuasi-monopolización del recurso y los bruscos avatares de la actividad, que alternaba entre ciclos de bonanza y épocas de crisis y decadencia (ZOLEZZI, 2004a).

A la luz de esos antecedentes surgen varios interrogantes. ¿Bajo qué condiciones se desarrolló la minería del wolframio en la Argentina durante el Siglo XX? ¿Ocupó un papel destacado en el concierto del sector minero nacional? ¿Hasta qué punto fue crucial para la industria militar de las

\footnotetext{
${ }^{1}$ Entre las principales aplicaciones no bélicas del wolframio, se cuentan la construcción de filamentos para lámparas incandescentes, resistencias eléctricas, electrodos, varillas para soldar, blancos para rayos X, alambres de plomo, motores, cátodos para tubos de poder, placas de distribuidores de automóviles y aeronaves, productos electrónicos, discos abrasivos, puntas de mechas y taladros excavadores para la búsqueda de petróleo.
}

${ }^{2}$ De todos los metales, el wolframio es el que se funde a mayor temperatura (3.410 grados Celsius). Después del carbón, es la materia prima industrial con más alto punto de fusión, lo cual le confiere notable resistencia a incendios. Respecto de su dureza, la mezcla entre tungsteno y carbón es tres veces más resistente que el acero. 
grandes potencias? ¿Cuáles fueron las estrategias desplegadas por el capital para controlar y explotar el recurso y qué políticas desarrolló el Estado al respecto? ¿Se verificaron fenómenos de acumulación por desposesión relacionados con las categorías de análisis propuestas por la teoría? Si así fue, ¿se trató de mecanismos similares a los actualmente observados en la mega-minería metalífera argentina actual, como la privatización y acaparamiento neocolonial de tierras y recursos, la expulsión de campesinos y aborígenes, la desestructuración de economías regionales, la precarización laboral, la apropiación corporativa de fondos públicos, la cooptación del Estado, el fraude y la ilegalidad, la violencia, el despojo ecológico y la desposesión del derecho a la salud? Expresado de otro modo: las dinámicas expropiatorias del extractivismo minero contemporáneo, ¿suponen la mera repetición de las desposesiones del pasado, pero a una escala mucho mayor?

Sobre la base de bibliografía especializada, estadísticas oficiales e información periodística, el presente artículo apunta a cubrir esa área de vacancia persiguiendo dos objetivos complementarios: a) reconstruir históricamente el desarrollo de la minería del wolframio en la Argentina durante la Primera y la Segunda Guerra Mundial y la Guerra de Corea mediante la recolección y análisis de la escasa y dispersa información disponible sobre la cuestión; y b) determinar si los boom resultantes de esas coyunturas bélicas implicaron para la Argentina el desarrollo de algunos de los mecanismos de acumulación por desposesión descriptos por la literatura teórica de referencia y que actualmente se hallan presentes en el sector minero argentino. Es importante aclarar que las ventanas de tiempo consideradas no se ceñirán estrictamente al desarrollo de las citadas coyunturas bélicas, sino que por razones lógicas abarcarán también los años previos y subsiguientes a las mismas.

El trabajo se estructura de la siguiente forma. De naturaleza teórica, el primer apartado define el concepto de acumulación por desposesión y discute la relación existente entre la minería metalífera, el belicismo y las dinámicas expropiatorias del capital. Núcleo del artículo, los siguientes tres acápites se encuentran enteramente dedicados a analizar las vicisitudes de la minería argentina del wolframio en el contexto de las dos grandes guerras mundiales y la Guerra de Corea. Finalmente, se presentan las principales conclusiones o reflexiones finales a las cuales ha arribado este trabajo.

\section{ACERCA DE LA RELACIÓN ENTRE BELICISMO, MINERÍA METALÍFERA Y ACUMULACIÓN POR DESPOSESIÓN}

El concepto de acumulación por desposesión se desprende de la noción marxista de acumulación primitiva u originaria. De acuerdo al marxismo clásico, la acumulación originaria constituyó el proceso histórico de despojo, violencia y pillaje que entre finales del Siglo XV y mediados del Siglo XVIII se abatió sobre el régimen feudal para instaurar las relaciones sociales capitalistas a escala mundial y forjar el stock de capital necesario para la primera Revolución Industrial. El cercamiento y privatización de las tierras comunales europeas, la expulsión masiva del campesinado, la sobreexplotación laboral, los salarios por debajo del nivel de subsistencia, la prohibición de la sindicalización de los obreros, los regímenes esclavistas y semi-esclavistas, la conquista y el saqueo colonial de América y el surgimiento de la deuda pública y el sistema internacional de crédito fueron los principales factores que contribuyeron a generar un cuantioso botín que refluyó hacia las metrópolis europeas para convertirse en capital (MARX, 1968).

Según la interpretación marxista ortodoxa, la acumulación primitiva u originaria moldeó la prehistoria del capital, operando como un acontecimiento momentáneo propio de toda etapa formativa del capitalismo en una sociedad atrasada. Sin embargo, Harvey (2004) sostiene que se trata de una fuerza importante y permanente de la geografía histórica del capital. La acumulación basada en la depredación, el fraude y la violencia nunca se limitó a una etapa 'original' ya superada, ni tampoco opera como algo 'exterior' al capitalismo como sistema cerrado (HARVEY, 2004; 2014). Antes bien, sus mecanismos reaparecen regularmente en distintos países y regiones a lo largo de distintas fases de desarrollo del sistema Dado que no es apropiado llamar "originario" o "primitivo" a algo que continúa ocurriendo actualmente, Harvey (2004) define al proceso en términos de acumulación por desposesión, argumentando que el saqueo es tanto un presupuesto genético como un mecanismos inherentes al capitalismo.

Siguiendo a Harvey $(2004 ; 2007 ; 2014)$, la acumulación por desposesión abarca todos los mecanismos de la acumulación primitiva reconocidos por el marxismo tradicional, pero no se limita a ellos. Así, a las categorías de análisis 'clásicas' -mercantilización y privatización de la tierra, expulsión y proletarización de campesinos y aborígenes, eliminación de formas de producción y consumo precapitalistas, apropiación colonial, neocolonial e imperial de recursos naturales, esclavitud, usura, 
deuda pública-, el geógrafo británico añade la flexibilización laboral, la privatización de empresas y servicios públicos, los derechos de propiedad intelectual, la mercantilización de la naturaleza, el despojo ecológico y las redistribuciones estatales -esto es, las políticas de transferencia de recursos económicos desde el erario público y los asalariados hacia las arcas del capital-.

Dado que el acceso fluido a las materias primas baratas y abundantes de la periferia siempre ha sido indispensable para asegurar la reproducción ampliada del capital en el centro del sistema, la minería metalífera ha sido históricamente un vehículo de las dinámicas expropiatorias del capitalismo. Según Marx (1968), las minas coloniales americanas fueron una de las fuentes de la acumulación originaria y Mandel (1969) demostró que los metales preciosos del Nuevo Mundo representaron una porción importante del valor del capital invertido en la industria europea hacia 1800. Con el paso del tiempo, la minería metalífera se tornó vital para la continuidad del capitalismo y el estilo de vida "moderno". Como lúcidamente explica Machado Aráoz (2014), la modernidad capitalista es una vivencia mineral: sin metales no habría Estado, mercado, familia, herencia, lujo, automóviles, aviones, industria, agricultura a gran escala, computadoras ni teléfonos celulares. Sin metales también desaparecería la industria más grande que ha existido desde un principio: la industria de la guerra.

Quisiéramos detenernos brevemente en el vínculo entre minería, belicismo y capitalismo. Siguiendo a Luxemburgo (1967), a lo largo de la historia del capital el militarismo ha ejercido una función perfectamente determinada que de modo sistemático ha estado presente en cada paso y fase de acumulación del sistema: en la conquista de nuevos territorios; en el imperialismo colonial; en la destrucción de las sociedades primitivas y la apropiación de sus medios de producción; en la proletarización violenta de los pueblos sojuzgados; en la imposición forzosa del libre comercio y la ejecución de deudas; en las luchas interimperialistas libradas entre los propios países capitalistas, que según Harvey (1990) deben ser entendidas como momentos constitutivos de la dinámica de acumulación capitalista per se y no como simples accidentes o aberraciones; y finalmente, como medio puramente económico de primer orden para la realización de la plusvalía.

Todo lo anterior guarda estrecha relación con la minería metalífera, actividad que condensa en sí misma la fuente y la base de las dos principales formas de poder del orden social capitalista: la guerra y las finanzas; las armas y la riqueza; el plomo y el oro; el terror y el encantamiento. Si se parte de la visión descarnada de Hobbes, la civilización nace de las armas; si se toma el idílico relato de Locke, la civilización nace de los metales preciosos y el dinero. Pero fue Marx quien fusionó ambas interpretaciones al demostrar que son dos expresiones del mismo fenómeno: no hay acumulación sin armas y, como éstas demandan capital, contribuyen paralelamente a dinamizar la economía. En los fundamentos del desarrollo capitalista residen, por un lado, el brillo cegador del oro, y por el otro, minerales mucho más prosaicos fundidos en el rojo oscuro de las armas. De ahí que, en última instancia, la minería metalífera opere como un componente fundamental de la ecuación de dominio imperial del capital (MACHADO ARÁOZ, 2014).

La relación entre guerra, minería y acumulación por desposesión asume así una lógica circular. Siempre al servicio de la acumulación, la conquista de nuevos recursos y territorios y la apertura de nuevos mercados, la industria bélica depende inexorablemente del tercer reino de la naturaleza, de donde obtiene las aleaciones que utiliza en tanques, aviones y flotas navales y los materiales presentes en satélites, microchips, radares y otros dispositivos ultramodernos (MACHADO ARÁOZ, 2014). En un escenario de conflicto militar, las facciones en pugna naturalmente procurarán monopolizar o al menos garantizarse el acceso irrestricto a las fuentes de minerales estratégicos para la producción de armamento. Si no existen reservas en la región donde circula la mayor parte del capital y las fronteras internas se cierran, aquél deberá buscar en otro lado o correr el riesgo de una devaluación (HARVEY, 1990). Por esa razón, la minería es el puente que articula la satisfacción de las necesidades del militarismo internacional con el desarrollo de distintas dinámicas expropiatorias en los países que proveen de metales a las naciones beligerantes; expresado de otro modo, ofrece una "solución espacio-temporal" (HARVEY, 2004) a las grandes potencias pero a costa de generar múltiples despojos en los países periféricos.

\section{PRIVATIZACIÓN Y EXTRANJERIZACIÓN DE TIERRAS Y RECURSOS NATURALES: LA MINERÍA DEL WOLFRAMIO EN ARGENTINA DURANTE LA PRIMERA GUERRA MUNDIAL}

Si bien el descubrimiento y explotación de los primeros yacimientos de wolframio de Argentina se produjo durante el quinquenio 1870-1874, la extracción de este metal recién cobró impulso a finales del Siglo XIX, cuando se hallaron los dos depósitos más ricos del territorio nacional: Los Cóndores y 
El Águila, en la provincia de San Luis (ANGELELLI, 1984). El verdadero boom, empero, comenzó con la inminencia y posterior desarrollo de la Primera Guerra Mundial. En 1910, cuando las potencias europeas se aprestaban a entrar en guerra, Argentina contaba con 84 minas de wolframio (ZOLEZZI, 2004b). Con el estallido del conflicto, el número de descubrimientos se incrementó aún más: sólo en San Luis, 183 de las 281 minas denunciadas entre 1910 y 1919 correspondían a este mineral (BENINATO y BLASCO, 2004). La fiebre se extendió a pequeños yacimientos y depósitos aluvionales de Córdoba, La Rioja, Salta, San Juan y Catamarca.

El primer ciclo de la minería argentina del wolframio se caracterizó por la privatización, concentración y extranjerización del subsuelo, el surgimiento de enclaves exportadores y el desarrollo de prácticas depredatorias que más adelante dificultarían la explotación del recurso. Sancionado en 1887, el Código de Minería había adoptado el espíritu liberal y privatista de la época al inaugurar un régimen sin antecedentes en el mundo: negaba al Estado argentino toda facultad para explotar su propio subsuelo, lo obligaba a concesionar el recurso al capital privado y consideraba a los yacimientos como un bien inmueble distinto y separado del suelo que los contenía (CATALANO, 1984). Al someter al recurso a un régimen exclusivo de usufructo privado, la legislación abrió así un nuevo campo a la mercantilización de la naturaleza y la acumulación capitalista, determinando que los yacimientos pasaran a ser comprados y vendidos entre particulares aunque en sí mismos -parafraseando a Harvey (2014)- no fueran producto del trabajo social.

Ejemplo de ello fueron los sucesivos cambios de manos que se produjeron en el caso de la ya citada mina de wolframio Los Cóndores. Si bien el yacimiento había sido descubierto en 1893 por un pirquinero que trabajaba como peón en un campo de la zona, quien denunció el hallazgo fue Medardo Aguirre, dueño de la estancia donde se emplazaba. Como resultado, la Dirección de Minería de la Provincia de San Luis le adjudicó a este último la concesión de la explotación (VARSAVSKY, 2005; DíAZ, 2017), hecho que supuso una flagrante trasgresión de la legislación vigente, puesto que el Código de Minería de la época establecía claramente que los derechos sobre el recurso correspondían a su descubridor y no al propietario de las tierras donde aquél se localizaba. Al no contar con capital suficiente para iniciar las faenas extractivas, en 1898 el empresario ganadero vendió la concesión de 108 hectáreas a la Casa Herwig, una firma radicada en Santa Fe que incorporó como principal accionista del proyecto a la mundialmente famosa compañía alemana Krupp. Surgió así la empresa HANSA Sociedad de Minas, que se instaló en la región para explotar la mina e instalar la primera planta de concentración de wolframio, exportando la producción hacia las industrias siderúrgicas y bélicas germanas (CATALANO, 1984).

Sin duda, lo anterior configuró el acta fundacional de un proceso de acumulación por desposesión basado en el acaparamiento imperial y la expoliación de recursos naturales. Evidentemente ejecutando sus planes de acuerdo a las instrucciones provenientes de su país de origen, HANSA se expandió sigilosamente hasta apoderarse del depósito El Águila -muy cercano a Los Cóndores- y la inmensa mayoría de los yacimientos cordobeses y puntanos (CATALANO, 2004). Paralelamente, y a medida que las relaciones entre Alemania y el resto de las potencias europeas iban tornándose más ásperas, la compañía teutona aceleró sus labores extractivas. Su producción en Los Cóndores-El Águila, por ejemplo, que a principios del Siglo XX no superaba las 335 toneladas anuales de wolframio, aumentó primero hasta llegar a las 800 toneladas para luego alcanzar un pico histórico de 1.600 toneladas en 1908, año en que el mencionado complejo minero se convirtió en el más importante de Sudamérica (BENINATO y BLASCO, 2004). Para 1910, cuando los preparativos para la inminente Primera Guerra Mundial habían reestructurado al mercado internacional de minerales metalíferos imponiendo la concepción de 'reservas estratégicas' (ZOLEZZI, 2004b), la empresa ya se había convertido en dueña de casi la totalidad de las minas de wolframio activas en Argentina, produciendo concentrados con una ley del $63 \%$ al $68 \%$.

Lamentablemente, las cifras de producción mencionadas más arriba no pueden ser debidamente cotejadas con las estadísticas de los organismos oficiales de la época. Los registros estatales recién se iniciaron en 1909, fecha a partir de la cual se constataron guarismos generales para toda la Argentina bastante inferiores a los citados previamente. La Tabla 1 y la Figura 1 muestran la serie histórica de la producción de concentrados de wolframio y la exportación de su principal sub-producto (el ácido tungstico) ${ }^{3}$ para el período 1909-1929, cubriendo así la fase previa al comienzo de la Primera Guerra Mundial, el desarrollo de la conflagración y los años posteriores a su fin. Allí se observa que la producción de wolframio mostró grandes oscilaciones hasta 1913, pero que a partir del

\footnotetext{
3 Hasta 1924 inclusive, cuando la serie estadística se interrumpe, las fuentes oficiales presentan datos de las exportaciones de wolframio según su contenido metálico neto en ácido tungstico para todo el período, no así en lo que atañe a las remesas de minerales concentrados de wolframio, que sólo están disponibles para algunos años.
} 
Mineração de metais, guerra e acumulação por desapropriação: o caso do tungstênio na Argentina durante os conflitos internacionais do Século XX

estallido del conflicto bélico inició una fase ascendente que la catapultó de apenas 2 toneladas en 1914 a nada menos que 510,8 toneladas en 1918, con un pico máximo de 756,3 toneladas en 1917.

Por su parte, las exportaciones de ácido tungstico se mantuvieron en niveles relativamente altos durante todo el decenio 1909-1919. Seguramente a raíz de la intensidad de los preparativos militares, la cifra más elevada se registró a comienzos de dicho sub-período ( 753,7 toneladas), llegando a representar más de la mitad (51\%) del valor bruto de producción de la rama minera metalífera. Luego de una tendencia declinante que se prolongó hasta 1915 inclusive (101,5 toneladas), el recrudecimiento de la contienda impulsó el raudo ascenso de las exportaciones a 512,6 y 687,8 toneladas en 1916 y 1917, respectivamente. Como puede apreciarse, si bien todo el wolframio extraído se remesaba al exterior -en Argentina aún no existían industrias que lo utilizaran como insumo-, las cifras oficiales de producción y exportación no guardan coherencia entre sí, puesto que las segundas superan en casi todos los años a las primeras. Probablemente esto deba atribuirse a la comercialización tardía de stocks acumulados en años anteriores.

Tabla 1 - Argentina: Producción y exportación de wolframio antes, durante y después de la Primera Guerra Mundial (en toneladas), 1909-1929.

\begin{tabular}{|c|c|c|}
\hline AÑO & Producción de concentrados de wolframio & Exportación de ácido tungstico \\
\hline 1909 & 527,604 & 753,720 \\
\hline 1910 & 58,060 & 449,400 \\
\hline 1911 & 0 & 371,882 \\
\hline 1912 & 353,210 & 409,984 \\
\hline 1913 & 0 & 344,984 \\
\hline 1914 & 2,010 & 262,127 \\
\hline 1915 & 77,740 & 101,509 \\
\hline 1916 & 681,495 & 512,605 \\
\hline 1917 & 756,300 & 687,840 \\
\hline 1918 & 510,840 & 379,377 \\
\hline 1919 & 114,710 & 125,306 \\
\hline 1920 & 11,640 & 27,617 \\
\hline 1921 & 0 & 31,156 \\
\hline 1922 & 0 & 84,066 \\
\hline 1923 & 12 & 63,442 \\
\hline 1924 & 0 & 47,355 \\
\hline 1925 & 0 & $\mathrm{~s} / \mathrm{d}$ \\
\hline 1926 & 0 & $\mathrm{~s} / \mathrm{d}$ \\
\hline 1927 & 9,153 & $\mathrm{~s} / \mathrm{d}$ \\
\hline 1928 & 22,875 & $\mathrm{~s} / \mathrm{d}$ \\
\hline 1929 & 58,890 & $\mathrm{~s} / \mathrm{d}$ \\
\hline
\end{tabular}

Fuente: elaboración personal sobre la base de DGMGyH (1911; 1925; 1929; 1930).

Figura 1 - Argentina: producción de wolframio y exportación de ácido tungstico antes, durante y después de la Primera Guerra Mundial (en toneladas), 1909-1929.

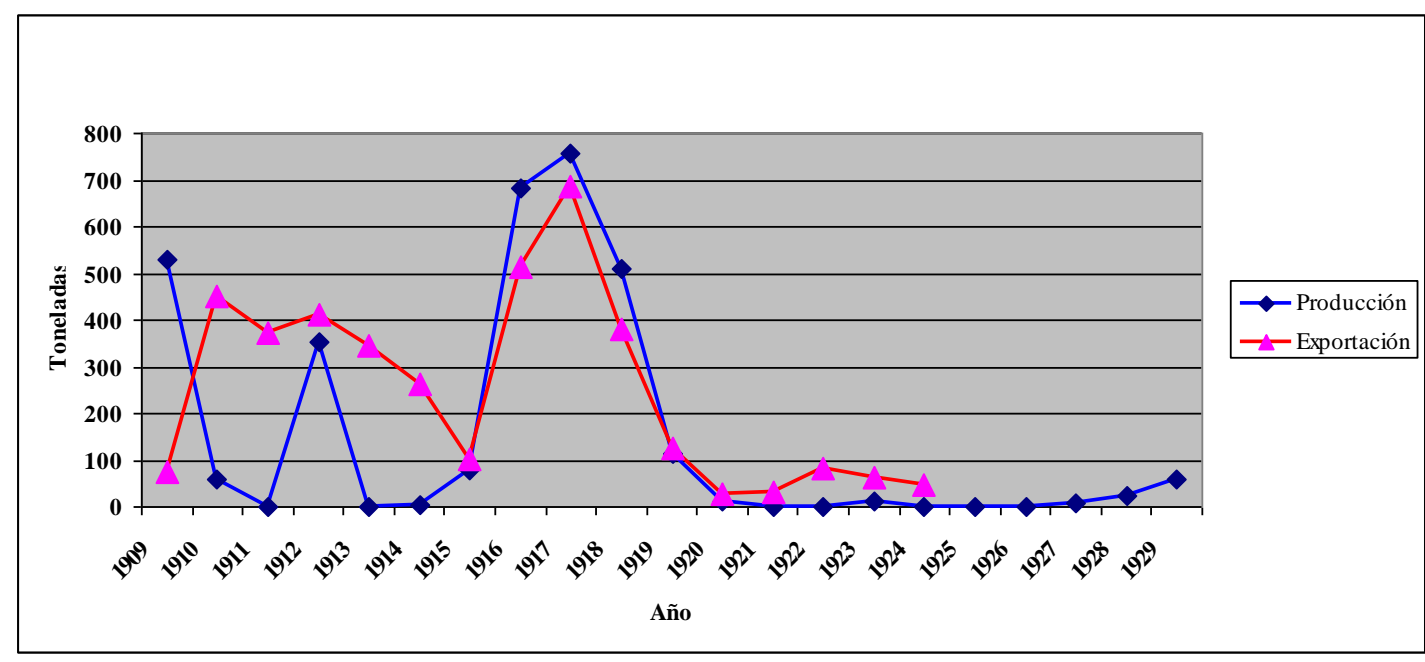

Fuente: elaboración personal sobre la base de DGMGyH (1911; 1925; 1929; 1930). 
Según se desprende del análisis de las estadísticas oficiales, durante esta fase el wolframio desempeñó un papel protagónico en la minería metalífera argentina. Con el 2,2\% del volumen global extraído, fue -después del plomo, el cobre y el antimonio (otro metal de uso bélico)- el rubro más producido entre 1909 y 1929 y el segundo más exportado hasta 1924 (26,52\%). Si se toma estrictamente como ventana de tiempo al marco de la Primera Guerra Mundial, el wolframio representó menos del $10 \%$ de la producción metalífera argentina, pero lideró las exportaciones de la rama de actividad, acaparando entre el 73,4\% y el 98,7\%. Aún así, entre 1913 y 1917 la participación argentina en la producción mundial de wolframio fue de apenas el $2 \%$, situándose muy por debajo de China, Birmania, Estados Unidos, Bolivia, Malasia, España, Portugal, Japón y Australia (CARUANA DE LAS CAGIGAS y GONZÁLEZ CALLEJA, 2014).

Paradójicamente, el control cuasi-monopólico de HANSA sobre el recurso doméstico no fue suficiente para lograr que el imperio alemán capitalizara plenamente el boom exportador argentino. Si bien durante los preparativos bélicos y el primer año de guerra el puerto de Hamburgo fue el destino casi excluyente de las remesas nacionales de wolframio (CATALANO, 1984; VARSAVSKY, 2005), esta situación pronto cambió. La estrategia británica de obstruir el abastecimiento alemán y el papel en ascenso de Estados Unidos como importador de bienes estratégicos para proveer al bloque aliado (RAYES, 2014) se tradujeron en un bloqueo naval que reorientó el flujo de wolframio hacia Inglaterra, América del Norte, Francia, Italia, Holanda y Bélgica (CATALANO, 1984), provocando serios trastornos a la economía de guerra germana (CARUANA DE LAS CAGIGAS y GONZÁLEZ CALLEJA, 2014). Este cambio obedeció exclusivamente a las circunstancias y dinámicas del conflicto interimperialista y resultó por completo independiente de las decisiones del gobierno argentino, que se empeñó en mantener una posición neutral para evitar enemistarse comercialmente con el Reino Unido y Alemania, principales compradores de sus productos agropecuarios y forestales.

Sin perjuicio de lo anterior, HANSA continuó explotando ininterrumpidamente sus minas de wolframio hasta el fin de la guerra. No menos importante, a lo largo de sus veinte años de presencia en Argentina la empresa llevó a cabo algunos despojos en materia laboral y productiva. No conforme con contar desde 1905 con el ferrocarril que le permitía abaratar el transporte de su producción desde San Luis hasta el puerto de Rosario (DÍAZ, 2017), HANSA recurrió a cuanto medio tuvo a su alcance para obtener ganancias rápidas sin incurrir en riesgo alguno. Aunque Beninato y Blasco (2004) destacan que la mina era trabajada con las herramientas y métodos más modernos de la época, otras fuentes indican que esto no fue tan así. Según Catalano (1984), durante la Primera Guerra Mundial la empresa aumentó su productividad (y rentabilidad) alentando a los pirquineros independientes de la región a que, bajo condiciones de extrema precariedad, arrancaran los filones más ricos de mineral y se los vendieran a bajo precio. Como resultado de esta estrategia -que podría ser interpretada como una forma primitiva de sub-contratación, tercerización o flexibilización de la fuerza de trabajo-, las minas fueron rapiñadas de tal manera que su reactivación se tornó extremadamente dificultosa durante las décadas posteriores al boom.

Esta táctica de acumulación basada en la elusión de riesgos laborales se torna más comprensible cuando se advierte que HANSA ya había sufrido conflictos gremiales antes del inicio de la guerra. En 1908, los 400 obreros y empleados de Los Cóndores-El Águila habían lanzado una dura huelga que, según crónicas periodísticas, alcanzó inusitada gravedad debido a la ausencia de fuerzas policiales en la zona (CATALANO, 2004). Si bien carecemos de elementos para determinarlo fehacientemente, no es descabellado especular que los detonantes hayan sido los mismos que provocaron situaciones similares en otras minas metalíferas argentinas de la época, como las largas y duras jornadas de trabajo, las riesgosas condiciones de seguridad, la precariedad habitacional y alimentaria y los bajísimos salarios. Al respecto, los operarios de HANSA no recibían sus remuneraciones en moneda nacional, sino en fichas acuñadas por la propia compañía, es decir, en los famosos "vales" canjeables a los que muchas empresas recurrieron durante este período para aumentar fraudulentamente sus ganancias a costa de sus obreros, cobrándoles precios inflados por las mercancías de primera necesidad vendidas en sus proveedurías.

Por completo dependiente de la coyuntura bélica, el primer ciclo del wolframio entró en decadencia ni bien finalizó la Primera Guerra Mundial y se agotó definitivamente pocos años después. Luego de que HANSA se retirara de Argentina en 1918, el $75 \%$ de las minas nacionales de wolframio se paralizó de forma casi inmediata. Sólo quedaron en operación algunas explotaciones del norte cordobés y salteño que corrieron igual suerte en 1920. Esta situación queda claramente reflejada en la Tabla 1 y la Figura 2, donde se muestra que tanto la producción como las exportaciones se redujeron a su mínima expresión desde 1920 en adelante, una vez declarada la paz entre los países beligerantes. 


\section{ACAPARAMIENTO DE RECURSOS, PRECARIZACIÓN LABORAL E ILEGALIDAD: EL IMPERIALISMO ESTADOUNIDENSE Y EL WOLFRAMIO ARGENTINO DURANTE LA SEGUNDA GUERRA MUNDIAL}

Potenciado por la crisis de 1929, el declive en Argentina de la minería del wolframio se extendió hasta 1932, año en el que la demanda mundial paulatinamente comenzó a aumentar ante las perspectivas del estallido de un nuevo conflicto bélico. Como explica Thomàs (2017), las fluctuaciones del precio del wolframio fueron un claro barómetro de los cambiantes presagios de paz y guerra de la época. Antes de la Conferencia Mundial de Desarme de Génova, las cotizaciones se desplomaron en respuesta a las expectativas de que las grandes potencias llegaran a un acuerdo que sentara las bases para una paz duradera, pero los precios comenzaron a subir rápidamente luego de que el fracaso del diálogo sugiriera la posibilidad de que a corto plazo se desatara una nueva conflagración. Como resultado, el rearme alemán ante los presagios de guerra propició entre 1932 y 1939 la eclosión de un segundo ciclo exportador del wolframio que, más intenso y duradero que el anterior, generó un nuevo episodio de acaparamiento imperial de tierras y recursos protagonizado ya no por los intereses germanos, sino por el capital estadounidense.

Como bien señala Cuvi (2011), durante esta época Estados Unidos tendió a crear instituciones y desarrollar un modus operandi que le permitieran controlar los recursos naturales de América Latina. Puesto que doce de los diecisiete rubros estratégicos requeridos por las milicias norteamericanas se hallaban al sur del río Bravo, el gobierno estadounidense se valió de sus relaciones diplomáticas, su poder bélico y su capacidad de crédito y compra para acaparar determinadas materias primas estratégicas -entre ellas, minerales metalíferos de uso bélico como el wolframio- y al mismo tiempo evitar que cayeran en manos de las potencias del Eje. Una de las agencias creadas para tal fin fue la Metal Reserves Company (CUVI, 2011).

Con respecto específicamente al caso del wolframio, mientras que la Alemania nazi se abastecía en gran medida de Asia y la región española de Galicia, los Países Aliados en general y los Estados Unidos en particular dependían, por un lado, del wolframio suministrado por los mayores exportadores de la época -China, Corea y la colonia británica de Birmania-, y por el otro, del wolframio de Indochina y los propios yacimientos norteamericanos. Sin embargo, la creciente demanda de wolframio para usos bélicos durante los preparativos para la contienda y a la invasión japonesa a China en 1937 hicieron temer que este insumo escaseara. Por esa razón, el gobierno estadounidense estimuló la producción de sus propias minas y diversificó sus compras a otros países productores occidentales, tales como Bolivia y Argentina (THOMÀS, 2017).

En Argentina, el gobierno norteamericano desplegó entre 1932 y 1944 una agresiva política de control monopólico de los yacimientos de wolframio. Dicha estrategia se desarrolló en gran medida a través del grupo Williams, así llamado por pertenecer a Thomas Williams, un poderoso industrial estadounidense que se desempeñaba como consejero y representante de la Metals Reserve Company. Con fuertes lazos con la banca norteamericana y grupos de Wall Street ligados a la dinastía Rockefeller, Williams ya controlaba directa o indirectamente a importantes empresas de la cúpula industrial argentina. Según Zolezzi (2004a), durante esta época el grupo Williams se convirtió en el "rey del wolframio" y lideró una suerte de trust vinculado a dicho metal que estaba integrado además por la Compañía Minas Argentinas, también surgida bajo la influencia de la Metals Reserve Company y presidida por miembros de la burguesía nacional (grupo Tornquist) y filiales de holdings extranjeros de materias primas como la National Lead Company y Louis Dreyfus.

A través de la Sociedad Minera Argentina (SOMINAR) y una pléyade de filiales y firmas vinculadas (Corporación Minera Argentina, Minerales y Metales, Compañía Puntana de Minerales, Compañía Minera Cerro Áspero, American Mining Company, Compañía Minera de Auti, Tungsteno de Auti, SOMICOR, SOMINOL, etc.), el grupo Williams se apoderó de las principales minas de Córdoba y San Luis. El acaparamiento comenzó en 1932, cuando SOMINAR compró por apenas 1.900 pesos moneda nacional ${ }^{4}$ los derechos mineros del complejo Los Cóndores-El Águila, que había sido rematado por la banca estatal en subasta pública después de más de una década de inactividad y abandono. En ese año, la misma empresa inició también la explotación del distrito cordobés La Bismutina. Sigilosamente, este proceso de mercantilización y privatización de tierras y recursos y apropiación imperial de reservas de materias primas estratégicas continuó durante los años previos a la Segunda Guerra Mundial. Para cuando estalló el conflicto, SOMINAR y las demás empresassatélite pertenecientes al grupo Williams ya controlaban y operaban los principales yacimientos de wolframio de Córdoba (Cerro Áspero/San Virgilio, Fischer, San Ignacio, Olaén, Los Mogotes,

${ }^{4}$ Esa cifra equivale a apenas 489 dólares de 1932 (aproximadamente 9.400 dólares actuales).

$\begin{array}{llll}\text { Caminhos de Geografia } \quad \text { Uberlândia-MG } & \text { v. 22, n. } 79 \quad \text { Fev/2021 } & \text { p. 18-38 }\end{array}$

Página 25 
Mineração de metais, guerra e acumulação por desapropriação: o caso do tungstênio na Argentina durante os conflitos internacionais

Characato Olaén, La Bismutina, Auti-Aguas de Ramón) y San Luis (El Morro, La Coquita, Los Avestruces, La Aspereza, Los Cóndores-El Águila). A esto debían añadirse las minas en manos de representantes, filiales indeterminadas y personas interpósitas y los pequeños depósitos de Catamarca (Buena Suerte/Los Viejos) y La Rioja (ANGELELLI, 1984; ZOLEZZI, 2004a) (Figura 2).

Figura 2 - Argentina: principales distritos mineros productores de wolframio según provincias y concesionarios, 1909-1969.

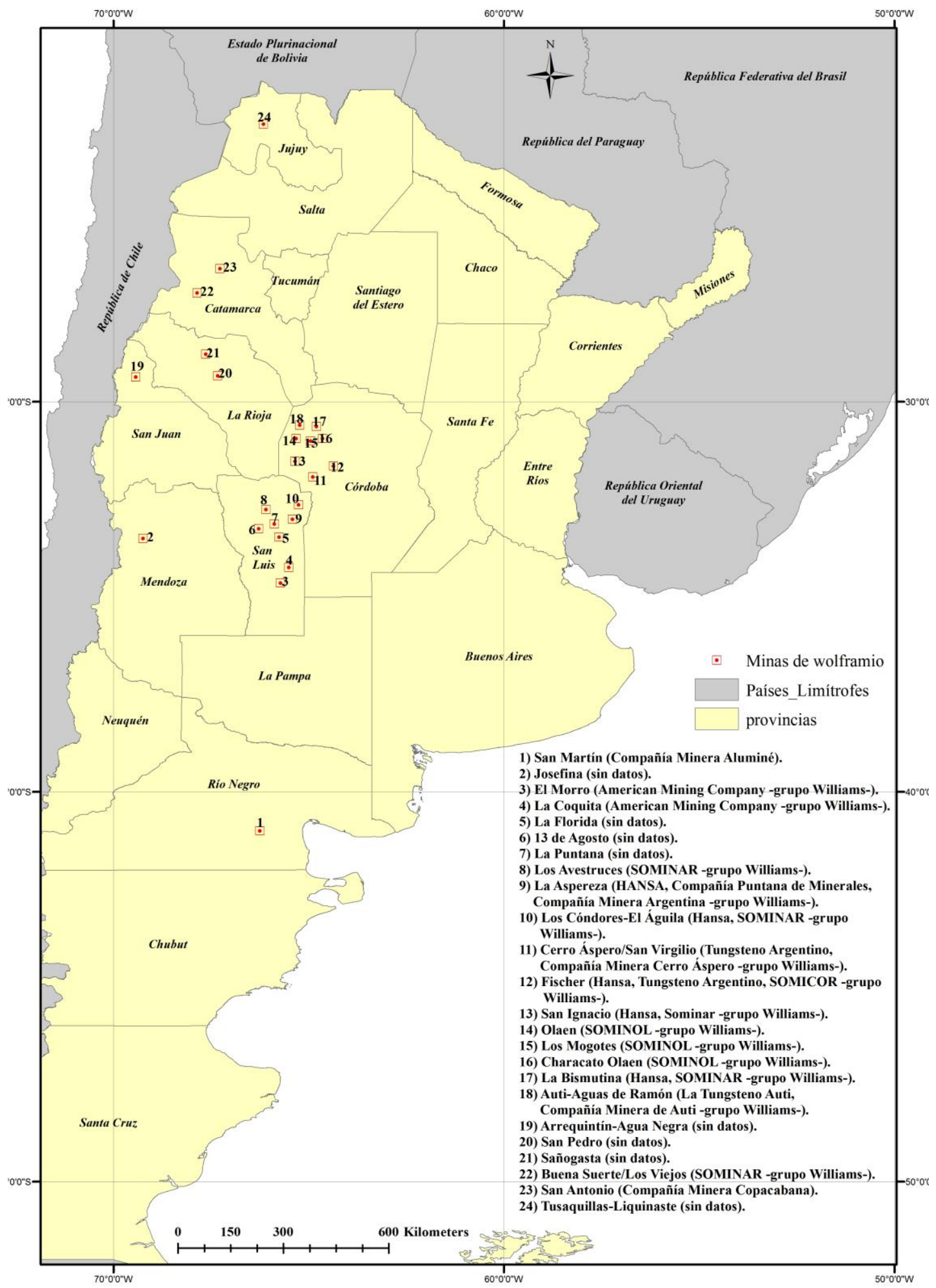

Fuente: elaboración personal en base a Angelelli (1984). 
Si bien a nivel nacional este fenómeno no despertó ninguna animadversión y fue tácitamente tolerado por los gobiernos conservadores de la época, no ocurrió lo mismo a escala provincial. En 1937, la sospechosa presencia del grupo Williams en la minería del wolframio determinó que el gobernador de Córdoba anulara por decreto todas las concesiones otorgadas a SOMINAR, reintegrándolas al patrimonio estatal para así impedir el monopolio privado de los recursos mineros provinciales y el acaparamiento de reservas estratégicas para los Estados Unidos. Urgida por la inminencia del conflicto bélico, la empresa recurrió a otros mecanismos de acumulación por desposesión, como el fraude y la ilegalidad. Por intermedio de compañías subsidiarias, SOMINAR solicitó cateos y permisos de exploración en zonas donde existían minas caducas o abandonadas desde finales de la Primera Guerra Mundial, pero en vez de ceñirse a las actividades autorizadas, se expandió hacia yacimientos cercanos que estaban siendo reintegrados al pleno dominio del Estado y comenzó a explotarlos sin control ni habilitación legal alguna. Denunciado en 1938 por personal de la Dirección Provincial de Minas y Geología, este plan de obstrucción, acaparamiento y depredación abarcaba 2.000 hectáreas (ZOLEZZI, 2004a) -es decir, 20 km2-, área 30 veces más grande que la superficie máxima $(0,63 \mathrm{~km} 2)$ que en ese momento el Código de Minería permitía para concesiones mineras.

Como era previsible, la denuncia derivó en 1939 en la sanción de un nuevo decreto que suspendió todos los cateos del grupo Williams en la provincia de Córdoba. Aún así, y después de largos litigios judiciales y políticos, el consorcio estadounidense logró la devolución de todos los derechos mineros anulados en 1937, así como también la adjudicación de todas las pertenencias pretendidas durante toda la década de 1930. Sólo en Córdoba, SOMINAR llegó a controlar casi 800 hectáreas, seis grupos mineros y 42 minas de wolframio valuadas en 4,5 millones de dólares, además de 32 minas de oro y 50 depósitos de vanadio, plata, plomo y zinc (ZOLEZZI, 2004b).

Cuando la guerra finalmente estalló, la existencia tanto de presiones cruzadas de actores externos e internos como de conflictos ideológicos preexistentes determinó que los responsables de la política exterior argentina adoptaran una conducta pendular con respecto a los Estados Unidos. Así, en 19391940 la transición de la estrategia de neutralidad formal a la política de no beligerancia insinuó cierta proximidad a los Países Aliados, la cual se consolidó durante el bienio siguiente. Sin embargo, cuando el golpe de Estado de 1943 puso fin a la hegemonía conservadora y Washington comenzó a cuestionar la retórica nacionalista de la cúpula militar en el poder y su intransigencia respecto de las presiones norteamericanas para que rompiera sus relaciones con las potencias del Eje, el resultado fue cierto distanciamiento relativo, no obstante el interés (por razones más pragmáticas que ideológicas) del gobierno nacional y el grupo Rockefeller para que las relaciones entre Estados Unidos y Argentina fueran más estrechas y cordiales (CORIGLIANO, 2009).

Como era de esperar, esta situación se reflejó en los abruptos vaivenes que mostró la política argentina con respecto al recurso. Al desatarse la Segunda Guerra Mundial, el wolframio y otros metales de uso bélico fueron sugestivamente excluidos de la clasificación oficial impuesta por los gobiernos de la época, que diferenciaba a los minerales "estratégicos" -es decir, a los recursos que, al no existir localmente, debían importarse- de los minerales "críticos" -esto es, aquellos con reservas disponibles en el subsuelo nacional cuya explotación debía ser alentada para sustituir importaciones, favorecer la industrialización argentina y mitigar la dependencia externa- (ROUGIER, 2012). Dicha exclusión permitió que la exportación de wolframio continuara sin pausa hasta agosto de 1941, cuando las remesas al exterior fueron prohibidas. Sin embargo, apenas tres meses después el gobierno nacional derogó toda restricción y firmó un convenio comercial con Estados Unidos en el cual la Metal Reserve Company se comprometía a adquirir durante un lapso de tres años la totalidad de la producción doméstica de cromo, torio, mica, berilo y (por supuesto) wolframio. En este último caso, dicho compromiso contemplaba la adquisición de 3.000 toneladas anuales a un precio de 21 dólares fijado en el puerto de Nueva York por cada unidad de 20 libras de wolframio concentrado al $65 \%$, estableciendo además un régimen de premios y castigos en función de si los niveles de pureza superaban o no alcanzaban ese umbral, respectivamente (ZOLEZZI, 2004a).

El convenio comercial con Argentina, el control ejercido sobre los yacimientos bolivianos y la creciente producción de las minas norteamericanas de wolframio determinaron que el poder imperial estadounidense contara con un nivel inédito de reservas para abastecer a su industria bélica y la de los Países Aliados. Como resultado, el continente americano se convirtió en el principal proveedor mundial del recurso, desplazando a Asia y, particularmente, a China (THOMÀS, 2017).

En Argentina la fiebre se desató. Numerosas minas entraron en explotación no sólo en Córdoba y San Luis, sino también en Catamarca, La Rioja, Mendoza y San Juan. Con 438 pedimentos, San Luis alcanzó el récord de minas de wolframio de toda su historia (BENINATO y BLASCO, 2004), mientras 
que tanto en esa provincia como en Córdoba proliferaban los lavaderos que extraían el preciado metal de las arenas de los arroyos de la zona. Como resultado, el wolframio, que en 1936 representaba sólo el $15,16 \%$ del valor bruto de producción del sector metalífero nacional, llegó a acaparar el $46,13 \%$ en 1943 , explicando el $63,24 \%$ de las exportaciones y convirtiéndose en el segundo recurso minero-geológico más importante, después del petróleo. Según Zolezzi (2004a), la Argentina, que hasta 1937 había sido el noveno productor mundial, se convirtió en 1943 en el séptimo, satisfaciendo el $10,5 \%$ de las importaciones norteamericanas.

El convenio comercial con la Metals Reserve Company vino a consolidar el proceso de expansión de la producción y las exportaciones inaugurado por los preparativos bélicos y el posterior estallido de la Segunda Guerra Mundial. Según las estadísticas oficiales, hasta 1935 la producción argentina de concentrados de wolframio había sido escasa y errática, y las remesas al exterior, prácticamente inexistentes. Entre 1936 y 1941, en cambio, tanto la extracción como las exportaciones crecieron sostenidamente, pasando de 655 a 1.564 toneladas y de 755 a 1.589 toneladas anuales, respectivamente. Sin perjuicio de lo anterior, el sub-período más dinámico coincidió con los años de plena vigencia del mencionado acuerdo comercial: 1942 (1.923 toneladas producidas y 1.636 toneladas exportadas), 1943 -pico máximo histórico, con 2.181 y 2.251 toneladas, respectivamente, equivalentes a casi el triple de las cifras de 1937- y 1944 (1.886 y 1.732,17 toneladas) (Tabla 2; Figura 3). Así pues, la influencia de la Segunda Guerra Mundial y del convenio con la Metals Reserve Company fue tan decisiva para el desarrollo del sector que la producción argentina de este mineral llegó a acumular 14.933,9 toneladas entre 1932 y 1945, explicando en sólo catorce años el 81,92\% del volumen extraído en casi cuatro décadas (18.229,6 toneladas entre 1909 y 1945).

Tabla 2 - Argentina: producción y exportación de wolframio antes, durante y después de la Segunda Guerra Mundial (en toneladas), 1930-1949.

\begin{tabular}{|c|c|c|}
\hline AÑO & Producción de concentrados de wolframio & Exportación de concentrados de wolframio \\
\hline 1930 & 91,33 & $\mathrm{~s} / \mathrm{d}$ \\
\hline 1931 & 19,91 & $\mathrm{~s} / \mathrm{d}$ \\
\hline 1932 & 6 & $\mathrm{~s} / \mathrm{d}$ \\
\hline 1933 & 0 & $\mathrm{~s} / \mathrm{d}$ \\
\hline 1934 & 366 & $\mathrm{~s} / \mathrm{d}$ \\
\hline 1935 & 1.164 & 539 \\
\hline 1936 & 655 & 640 \\
\hline 1937 & 764 & 755 \\
\hline 1938 & 1.054 & 1.039 \\
\hline 1939 & 1.155 & 1.187 \\
\hline 1940 & 1.250 & 1.216 \\
\hline 1941 & 1.564 & 1.589 \\
\hline 1942 & 1.923 & 1.636 \\
\hline 1943 & 2.181 & 2.251 \\
\hline 1944 & 1.886 & $1.732,17$ \\
\hline 1945 & 965,9 & 494,37 \\
\hline 1946 & 101 & 481,88 \\
\hline 1947 & 83 & 102,85 \\
\hline 1948 & 203 & 47,19 \\
\hline 1949 & 158 & 0 \\
\hline
\end{tabular}

Fuente: elaboración personal sobre la base de DMyG (1935; 1940; 1948) y DNM (1953). 
Figura 3 - Argentina: producción y exportación de wolframio antes, durante y después de la Segunda Guerra Mundial (en toneladas), 1930-1949.

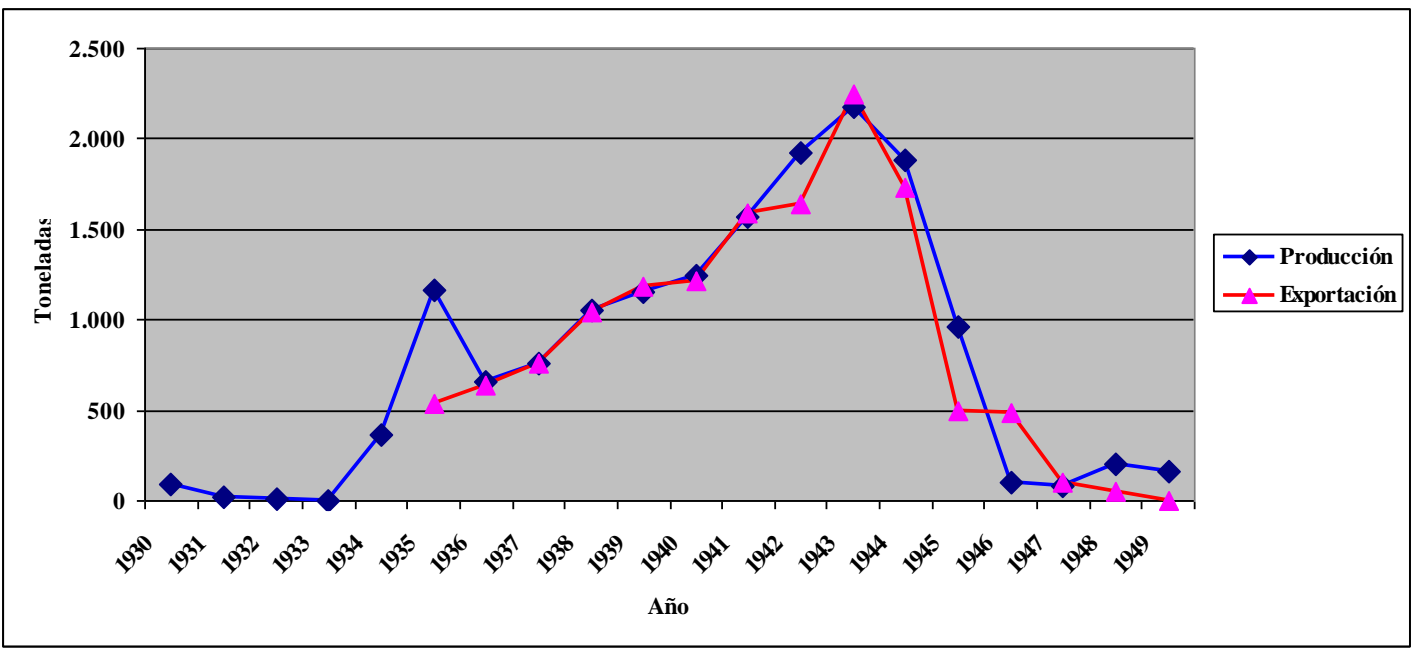

Fuente: elaboración personal sobre la base de DMyG (1935; 1940; 1948) y DNM (1953).

Si bien varias firmas nacionales y extranjeras se sumaron al boom, el principal beneficiario del acuerdo comercial con Estados Unidos fue sin duda el grupo Williams. De hecho, SOMINAR era la principal firma productora de wolframio de Argentina debido a la gran cantidad de minas que controlaba y el dinamismo del complejo Los Cóndores-El Águila, la mayor concentración de wolframita y scheelita conocida en el territorio nacional (ANGELELLI, 1984). Se estima que SOMINAR controlaba más del $60 \%$ de la producción nacional, sin contar la participación de las demás empresas del grupo Williams (ZOLEZZI, 2004a). Gran parte del predominio de SOMINAR y sus filiales provenía de dos factores adicionales: su fluido acceso al financiamiento del City Bank de New York y el National Bank Boston, que le permitió mecanizar y tecnificar sus minas y controlar el eslabón comercial del circuito; y las precarias condiciones a las que sometía a su fuerza laboral.

En lo que concierne al primer punto, la costosa incorporación de equipos, procedimientos y maquinaria obedecía a la baja ley del mineral (3\%), que obligaba a desarrollar sistemas de concentración que permitieran obtener los niveles de pureza $(65 \%)$ demandados por el mercado mundial. Esto convirtió rápidamente a SOMINAR en el líder del mercado, puesto que tales inversiones eran impensables para las minas operadas por pequeños y medianos productores que carecían de recursos propios y acceso el crédito, y menos aún para los tanteros y pirquineros independientes que explotaban los filones con métodos artesanales. Para ilustrar las diferencias de rentabilidad, en las minas más grandes y modernas -como las del grupo Williams- las pérdidas sufridas en el proceso de concentración rondaban el 15\%, mientras que para los pequeños mineros que concentraban a mano el producto alcanzaban el 50\% (CATALANO, 2004). SOMINAR capitalizó esas asimetrías en beneficio propio, dado que su fácil acceso el crédito le permitió convertirse en proveedor de insumos, equipos, explosivos y herramientas para todas las demás empresas del sector. Paralelamente, el grupo Williams controlaba las exportaciones a través de Minerales y Metales, filial que canalizaba la mayor parte de los flujos comerciales de wolframio.

Con respecto al mercado laboral, el segundo ciclo del wolframio se caracterizó por la relativamente abundante creación de puestos de trabajo: en 1941, la actividad había generado alrededor de 11.000 empleos directos (CATALANO, 2004). Sin embargo, en la principal mina de la época (Los CóndoresEl Águila) la fuerza de trabajo era predominantemente de origen extranjero (alemán, polaco, boliviano y chileno) (VARSAVSKY, 2005), algo a lo cual contribuían las riesgosas condiciones de explotación y las emanaciones de gases tóxicos en el interior de la mina, que rápidamente hicieron desistir a varios mineros argentinos de continuar trabajando en el complejo. En las minas cordobesas de SOMINAR la situación era aún peor: según la Dirección Provincial de Minas y Geología, la empresa no explotaba los yacimientos directamente, sino que lo hacía por contrato a cuenta y riesgo de mineros que trabajaban al pirquén, a destajo -es decir, sin un salario fijo, dependiendo su remuneración del volumen diario extraído- y sin vigilancia, dirección técnica y ni seguro laboral. De estas rudas faenas 
participaban mujeres e incluso niños de 5 o 6 años de edad, en flagrante violación de todas las leyes laborales y humanitarias (ZOLEZZI, 2004a).

Por otra parte, las consecuencias del boom del wolframio en general y del acuerdo comercial con la Metals Reserve Company en particular fueron lesivas para los intereses nacionales. Para empezar, la Argentina dejó de exportar wolframio a otros mercados (Inglaterra, Bélgica, Alemania, Francia, Suecia, Países Bajos, Japón) para concentrarse exclusivamente en un único destino. Esto aumentó su vulnerabilidad ante un eventual desplome de la demanda, como finalmente ocurrió cuando, poco antes de la culminación de la guerra, los Estados Unidos alcanzaron una situación de sobreabastecimiento, con importaciones que más que duplicaban la demanda (THOMÀS, 2017). Ante el cúmulo de reservas almacenadas, la Metals Reserve Company canceló unilateralmente el convenio con la Argentina a fines de noviembre de 1944, y en 1945 -una vez finalizada la guerra- decidió no renovar los contratos y comprar remanentes a precios muy bajos (DNM, 1953).

Dadas las características oligopólicas del mercado y el uso casi exclusivamente militar del wolframio, los precios cayeron y la actividad se paralizó en Argentina. Lejos de la bonanza registrada entre 1936 y 1941, cuando la cotización de la tonelada de concentrados de wolframio había trepado de 447,72 dólares a su pico máximo de 1.583,38 dólares ${ }^{5}$, los precios se redujeron de 1.440,30 dólares en 1944 a 913,46 dólares en 1946. Aunque la Metals Reserve Company accedió a regañadientes a bonificar a los productores mineros argentinos con efecto retroactivo para resarcirlos de parte de las pérdidas ocasionadas por la cancelación del acuerdo (DNM, 1948), la situación se agravó debido a la sanción en Estados Unidos de la Ley de Reservas de Minerales Estratégicos y Críticos, que a partir de 1946 facultó al gobierno norteamericano para disponer discrecionalmente de las ingentes acumulaciones de wolframio derivadas de su exitosa política previa de acaparamiento comercial. Estados Unidos utilizó esas reservas para deprimir deliberadamente los precios en determinadas épocas mediante la liberación puntual de stocks, lo cual provocó cierre de varias minas marginales en los países emergentes -la Argentina entre ellos- (CATALANO, 2004). Después de la tibia recuperación de los precios registrada en 1947, las cotizaciones disminuyeron aún más durante los años siguientes, cayendo a 453,72 dólares en 1949.

Sistemáticamente excluida de la política de crédito minero implementada en 1941 por el gobierno nacional debido a sus altos niveles de vulnerabilidad y dependencia de la coyuntura bélica, la minería argentina del wolframio entró así en una crisis profunda y casi terminal que ocasionó la paralización de más de un millar de minas y la brutal caída de la producción, que se redujo a apenas 83 toneladas en 1947 y 58 toneladas en 1949 (Tabla 2). Al culminar la guerra, los pequeños y medianos productores nacionales se vieron obligados a abandonar la actividad, dado que los precios internacionales no amortizaban sus costos de explotación ni siquiera excluyendo del cálculo a los gastos de transporte (SGROSSO, 1945). Con altibajos, SOMINAR continuó operando Los CóndoresEl Águila entre 1947 y 1949, pero luego la paralizó y despidió a todo su personal sin respetar la legislación laboral vigente, que la obligaba a pagarles doble indemnización. Esto derivó en un conflicto que debió ser resuelto por el gobierno provincial, que falló a favor de los obreros.

\section{DEL ÚLTIMO BOOM EXPORTADOR AL DEFINITIVO OCASO DE LA ACTIVIDAD: LA MINERÍA DEL WOLFRAMIO Y LAS REDISTRIBUCIONES ESTATALES DURANTE LA GUERRA DE COREA}

Al finalizar la Segunda Guerra Mundial, la Argentina consolidó su viraje desde el conservadurismo hacia el nacionalismo populista, utilizando tanto las divisas acumuladas a raíz de las exportaciones de alimentos y materias primas a las naciones beligerantes como las políticas intervencionistas de captación y redistribución de la renta agropecuaria para intensificar el proceso de industrialización sustitutiva de importaciones, ampliar el mercado interno y mejorar las condiciones de vida y trabajo del proletariado. Sin sufrir cambios importantes, esta situación se prolongó hasta el quinquenio 1949-

\footnotetext{
${ }^{5} \mathrm{~A}$ título comparativo, vale la pena destacar que aunque dicho valor era irrisorio frente al de metales preciosos como el oro (según el año, entre 848.623 y 1.285.216 dólares por tonelada), el wolframio representaba en ese momento cerca de la mitad del valor bruto de toda la producción minera argentina y era el mineral metalífero industrial más cotizado del país. De hecho, el wolframio no sólo duplicaba y septuplicaba el precio del estaño (689,66 dólares por tonelada) y la plata (214,80 dólares por tonelada), respectivamente, sino que además era entre 27 y casi 100 veces más valioso que el plomo (56 dólares por tonelada), el cobre (18,36 dólares por tonelada) y el zinc (15,25 dólares por tonelada) (véase DMyG, 1946).
}

$\begin{array}{lllll}\text { Caminhos de Geografia } & \text { Uberlândia-MG } & \text { v. 22, n. } 79 & \text { Fev/2021 } & \text { p. 18-38 }\end{array}$


1953, cuando las señales de debilitamiento del modelo de acumulación (desequilibrios en la balanza de pagos, crisis agrícola, cierto endeudamiento externo) comenzaron a tornarse evidentes.

Con el casi simultáneo estallido de la Guerra de Corea, el gobierno argentino ensayó un nuevo curso de acción que, sin todavía revertir radicalmente sus políticas populistas, implicó cierto acercamiento al país del norte mediante la rúbrica de acuerdos con petroleras y automotrices norteamericanas, la sanción de una nueva ley de inversiones extranjeras y la gestión de créditos con el Eximbank para desarrollar la siderurgia. Buscando evitar que la Argentina quedara apartada del mercado estadounidense en caso de que el conflicto bélico en Asia se prolongara, el Estado nacional ratificó el Tratado Interamericano de Asistencia Recíproca -que acordaba la defensa mutua entre los países firmantes- e incluso proyectó el envío de tropas a Corea para apoyar a las milicias norteamericanas, idea esta última que fue abortada por la resistencia obrera (KABAT, 2018).

Fue en el marco de esta condescendiente y genuflexa actitud del gobierno nacional que se desarrolló el tercer (y último) boom de la minería del wolframio. Dado que tanto la suspensión de la entrega de suministros de wolframio por parte de la China comunista como el estallido del conflicto coreano y la 'guerra fría' con la Unión Soviética habían privado a la industria bélica norteamericana de acceder a nuevas reservas de este metal, Estados Unidos aprovechó el acercamiento argentino para nuevamente intensificar sus estrategias de control imperial sobre los depósitos de wolframio del territorio nacional. Impulsada por la agudización de la conflagración en el sudeste asiático, la escalada de las cotizaciones internacionales fue propicia para que se desatara una nueva fiebre del wolframio en Argentina, inaugurando la fase $B$ del ciclo exportador iniciado durante los años treinta.

Se reactivaron así varias minas, entre ellas el complejo El Águila-Los Cóndores en San Luis, donde la ya citada compañía norteamericana SOMINAR reemplazó su antigua planta de concentración por otra de última generación traída desde Estados Unidos mediante un préstamo de 5 millones de dólares concedido por el Eximbank. Si bien se trató del caso más importante, no fue el único. De la mano de pequeñas y medianas firmas de capitales nacionales, numerosas minas resurgieron en San Luis, Córdoba, La Rioja, Catamarca y San Juan, mientras varios compradores argentinos y extranjeros recorrían febrilmente el territorio argentino para adquirir a altos precios -entre 10 y 12 pesos por kilogramo6- los sobrantes de wolframio rescatados de las escombreras y relaves de los yacimientos explotados durante la Segunda Guerra Mundial (ZOLEZZI, 2004a).

A diferencia de lo ocurrido durante las dos grandes conflagraciones mundiales, en esta ocasión el Estado nacional procuró aprovechar la favorable coyuntura generada por la Guerra de Corea para desplegar políticas orientadas a regular el mercado del wolframio y otros minerales de uso bélico. Buscando formar un stock de reserva, mejorar la competitividad internacional del sector y fortalecer el incipiente movimiento cooperativo, el gobierno argentino sancionó el decreto 9.782/50, que creaba agencias de rescate o compra del mineral, las cuales estaban obligadas a adquirir las partidas ofrecidas por los mineros, aunque éstos podían vender su producción a agentes privados que les pagaran mejores precios. El objetivo era generar un mercado seguro y estable ante los altibajos externos y evitar que, cuando culminara el conflicto coreano, se repitiera la desintegración de la actividad ocurrida luego del fin de ambas guerras mundiales (CATALANO, 1984).

Sin embargo, los abusos de comerciantes, intermediarios y especuladores que competían con la actividad de las agencias de rescate pronto determinaron que el Estado debiera intensificar su presencia en el sector para imprimir mayor transparencia al mercado, evitar la exportación ilegal y la venta clandestina de mineral de origen desconocido y proteger al pequeño productor minero de prácticas desleales. Así, en 1951 el decreto 8.630 puso a las agencias de rescate bajo la órbita del Instituto Argentino de Promoción del Intercambio (IAPI) y fundó el monopolio estatal sobre las compras de wolframio, fijando periódicamente cupos exportables y precios mínimos para los productores (CATALANO, 2004). Sin embargo, y aunque la Constitución Nacional de 1949 dejaba parcialmente obsoleto al viejo Código de Minería al declarar a los recursos minerales como propiedad imprescriptible e inalienable de la Nación, el gobierno no estatizó la explotación del wolframio, que continúo enteramente en manos privadas. Paralelamente, el Estado nacional lanzó un plan de reactivación de la actividad otorgando créditos a pequeños y medianos mineros.

Coincidiendo con el tramo más álgido de la Guerra de Corea, la nueva política regulatoria tuvo tal gravitación sobre la minería del wolframio que durante el cuatrienio 1950-1953 la extracción creció

${ }^{6}$ Conforme a la cotización del dólar estadounidense en la Argentina vigente en ese año (1950), eso significa que cada tonelada de wolframio residual costaba entre 626,3 y 751,6 dólares de 1950 (entre 7.300 y 8.700 dólares actuales). 
Mineração de metais, guerra e acumulação por desapropriação: o caso do tungstênio na Argentina durante os conflitos internacionais do Século XX

casi 30 veces -pasó de apenas 21,357 a 640,538 toneladas anuales- y las remesas al exterior (842,754 toneladas) absorbieron el $65,17 \%$ de la producción (1.293,232 toneladas) (Tabla 3; Figura 4), con los Estados Unidos como destino casi excluyente. Más importante aún, el wolframio representaba en 1953 más de la mitad (59,14\%) del valor exportado por el sector minero metalífero nacional, aunque apenas explicaba el 16,37\% del valor y el 0,43\% del volumen de producción global de dicha rama de actividad. El particular desenlace de la guerra ${ }^{7}$ y los presagios de nuevos conflictos bélicos mantuvieron relativamente altas las cotizaciones del wolframio hasta 1956, año en el cual las exportaciones argentinas de este mineral alcanzaron el pico máximo de la fase (2.082,316 toneladas) y representaron el $76,22 \%$ del valor de las remesas del sector metalífero.

Tabla 3 - Argentina: producción y exportación de wolframio durante y después de la Guerra de Corea (en toneladas), 1950-1969.

\begin{tabular}{|c|c|c|}
\hline AÑO & Producción de concentrados de wolframio & Exportación de concentrados de wolframio \\
\hline 1950 & 21,357 & 236,314 \\
\hline 1951 & 122,337 & 28,323 \\
\hline 1952 & 509 & 150,734 \\
\hline 1953 & 640,538 & 427,383 \\
\hline 1954 & 922,452 & 0 \\
\hline 1955 & 915,299 & 757,628 \\
\hline 1956 & $1.109,512$ & $2.082,316$ \\
\hline 1957 & 1.137 & $\mathrm{~s} / \mathrm{d}$ \\
\hline 1958 & 918,241 & $\mathrm{~s} / \mathrm{d}$ \\
\hline 1959 & 728,333 & $\mathrm{~s} / \mathrm{d}$ \\
\hline 1960 & 749,006 & 350 \\
\hline 1961 & 746,886 & 15 \\
\hline 1962 & 500,452 & 1.975 \\
\hline 1963 & 143,814 & $1.042,500$ \\
\hline 1964 & 55,700 & 4,747 \\
\hline 1965 & 130 & 24,700 \\
\hline 1966 & 130,705 & 50 \\
\hline 1967 & 204,007 & 107 \\
\hline 1968 & $\mathrm{~s} / \mathrm{d}$ & $\mathrm{s} / \mathrm{d}$ \\
\hline 1969 & $\mathrm{~s} / \mathrm{d}$ & $\mathrm{s} / \mathrm{d}$ \\
\hline
\end{tabular}

Fuente: elaboración personal sobre la base de SM (1958a; 1958b), SElyM (1965) y SEElyM (1968a; 1968b; 1968c).

Figura 4 - Argentina: producción y exportación de wolframio durante y después de la Guerra de Corea (en toneladas), 1950-1969.

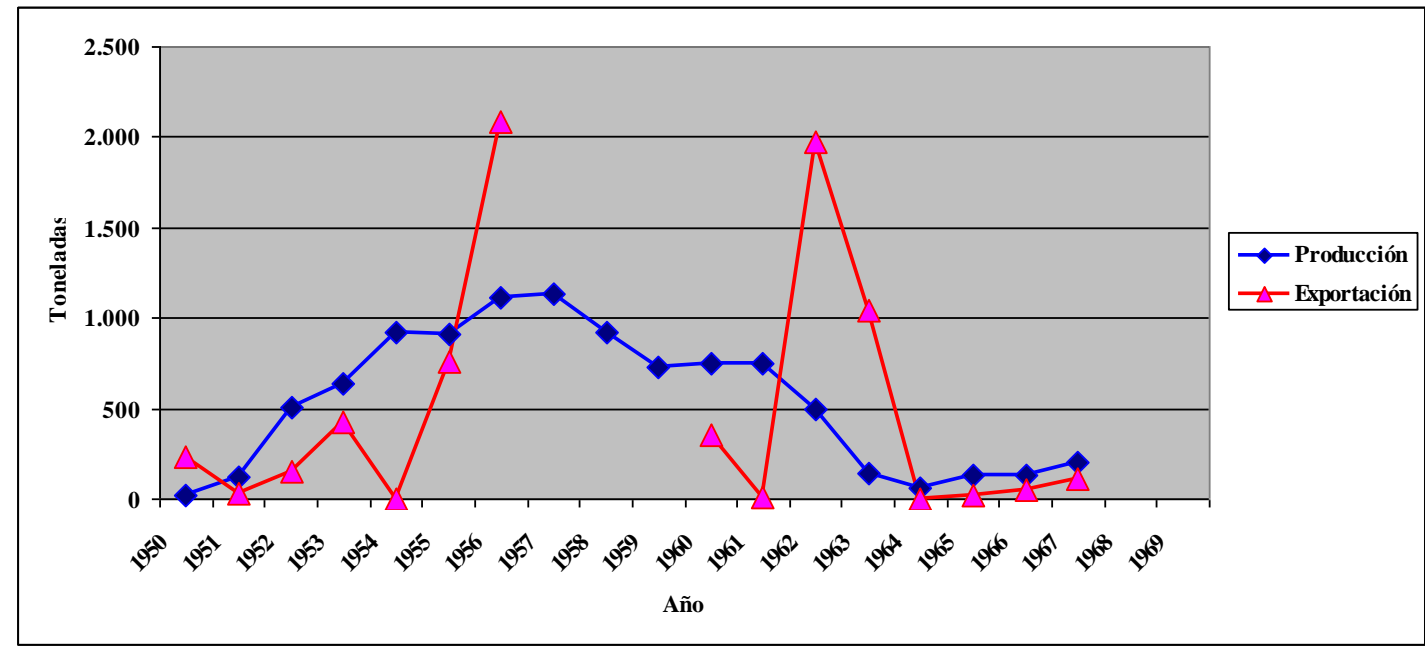

Fuente: elaboración personal sobre la base de SM (1958a; 1958b), SElyM (1965; 1968a; 1968b; 1968c).

\footnotetext{
7 Corea posee importantes reservas de tungsteno. Al culminar el conflicto, el regreso a la situación previa a la guerra -la división de la nación coreana en Corea del Norte y Corea del Sur- determinó que Estados Unidos perdiera toda posibilidad de acceder a los depósitos de wolframio bajo control de la facción comunista.
}

$\begin{array}{lllll}\text { Caminhos de Geografia } \quad \text { Uberlândia-MG } & \text { v. 22, n. } 79 & \text { Fev/2021 } & \text { p. 18-38 Página } 32\end{array}$ 
Al igual que durante la Segunda Guerra Mundial, el principal favorecido por el nuevo boom del wolframio fue el grupo Williams. Aunque los objetivos iniciales de la intervención gubernamental en el mercado eran loables, el espíritu de esta política rápidamente degeneró en otro mecanismo de acumulación por desposesión: las redistribuciones estatales, es decir, el conjunto de expropiaciones económico-políticas (reformas tributarias, subsidios, exenciones fiscales, ventajas comerciales y financieras, salvatajes de empresas, perdón de deudas corporativas, captura de organismos reguladores) que saquean el tesoro público para generar una producción política de rentabilidad que recompone la tasa de ganancia del capital y drena recursos hacia los centros del capitalismo mundial (HARVEY, 2007; 2014; MACHADO ARÁOZ, 2010).

Si bien el decreto 8.630/51 claramente establecía que quienes poseyeran inventarios de wolframio eran simples depositarios de la producción y que, en tanto tales, estaban obligados a venderla a las agencias del IAPI (DNM, 1953), SOMINAR aprovechó su posición dominante en el mercado para negarse rotundamente a comercializar sus partidas de mineral. Ante tal circunstancia, al gobierno argentino no le quedó otra alternativa que llegar a un acuerdo con Minerales y Metales, la filial comercial del grupo norteamericano Williams. Formalizado en marzo de 1952, el convenio determinaba que, hasta junio de 1958, el IAPI se comprometía a comprar todos los saldos exportables de wolframio que produjera SOMINAR y venderlos a Minerales y Metales junto a todo otro volumen adicional de wolframio que el organismo estatal juzgara conveniente comerciar por su intermedio (ZOLEZZI, 2004a). Como resultado, el monopsonio estatal encarnado por las agencias de rescate del IAPI se convirtió en la fachada que ocultaba la oligopolización privada del mercado, y en gran medida su función quedó reducida a la de ser un mero intermediario entre el eslabón extractivo (SOMINAR) y el eslabón comercial (Minerales y Metales) del grupo Williams.

Conforme al acuerdo, el precio al que Minerales y Metales adquiriría el wolframio que le vendiera el IAPI sería fijado según las fluctuaciones del promedio del mercado de Nueva York -deducidos costos y gastos-, pero en ningún caso podría ser inferior a los 45 dólares por unidad de 20 libras $(9,07 \mathrm{~kg}$.) al $65 \%$ de pureza (ZOLEZZI, 2004a) -esto es, 4.961 dólares por tonelada-. No obstante, esta cláusula jamás se cumplió y el convenio condujo a la descapitalización del IAPI.

Cotejando la evolución de los precios mínimos garantizados por las agencias de rescate con las estadísticas oficiales del volumen y valor bruto de producción de wolframio y ajustando esas cifras según la variación anual de la cotización del dólar en la Argentina, es fácil observar que el acuerdo erosionó la rentabilidad de la intervención del Estado nacional en el mercado del wolframio. A finales de 1951, antes de rubricar el convenio, el Estado adquiría las partidas de wolframio a razón de 35 pesos por kilogramo (DNM, 1953), cifra que, según el tipo de cambio entonces vigente, equivalía a 1.473 dólares por tonelada (17.000 dólares corrientes). A juzgar por los datos disponibles acerca del volumen y valor bruto de producción, el wolframio argentino se vendía a un promedio de 1.986 dólares por tonelada, aportando a las agencias estatales de rescate un margen de ganancia del $35 \%$.

En 1953, ya con el acuerdo en plena vigencia, las presiones de SOMINAR para que el IAPI elevara los precios mínimos de compra determinaron que el organismo estatal pagara 55,19 pesos por kilogramo (ZOLEZZI, 2004a), o lo que es igual, 2.446 dólares por tonelada. Sin embargo, esa misma tonelada se vendía a 2.232 dólares en los mercados de exportación, lo cual determinaba que el erario público absorbiera una pérdida neta del $8,7 \%{ }^{8}$. Como resultado, lo que comenzó siendo un negocio bastante lucrativo para el Estado se convirtió, a raíz del convenio con SOMINAR y Minerales y Metales, en un subsidio encubierto al capital extranjero, puesto que el IAPI, al comprar caro y vender barato a dos filiales del mismo grupo oligopólico, acababa transfiriendo -con creces- el excedente otrora captado por el tesoro público a las arcas privadas ${ }^{9}$.

\footnotetext{
${ }^{8}$ Al referirse al valor bruto agregado de toda la producción nacional de wolframio, los datos disponibles no discriminan qué proporción de la misma fue adquirida por Minerales y Metales ni explicitan el precio pagado por esa compañía. Sin embargo, el acuerdo contemplaba tanto el mineral extraído por SOMINAR como los concentrados vendidos al IAPI por terceros, de lo cual se desprende que la filial comercial del grupo Williams canalizó la mayor parte. Teniendo en cuenta que el valor bruto de producción refleja el precio final de venta y no el que Minerales y Metales efectivamente pagó por el tungsteno del IAPI, es razonable deducir que la pérdida sufrida por el organismo estatal fue mayor a la aquí estimada.

${ }^{9}$ Sin perjuicio del papel desempeñado por SOMINAR y Minerales y Metales, debe destacarse que el resto del sector también fue responsable de la descapitalización de las agencias de rescate. Buscando ganancias fáciles a corto plazo rapiñando los filones más ricos para rentabilizar aún más los altos precios garantizados por el IAPI, las pequeñas y medianas empresas de capitales nacionales habían continuado desarrollando las mismas
}

$\begin{array}{lllll}\text { Caminhos de Geografia } & \text { Uberlândia-MG } & \text { v. 22, n. } 79 & \text { Fev/2021 } & \text { p. 18-38 }\end{array}$


Para 1956, cuando el ciclo de precios internacionales altos había concluido y el golpe de Estado perpetrado un año antes había abortado el modelo nacionalista populista, la situación se tornó insostenible y el gobierno argentino renunció al manejo exportador de wolframio, delegándolo en las empresas del grupo Williams. Esta decisión asestó un duro golpe a la legitimidad del IAPI (ZOLEZZI, 2004a), que fue eliminado poco después. Durante el lapso de poco más de un año durante el cual el mercado del wolframio estuvo transitoriamente desregulado, la producción de concentrados alcanzó los valores máximos de la fase (1.137 toneladas anuales), aunque no es posible dimensionar la evolución de las exportaciones, cuya serie histórica se interrumpe durante este breve lapso debido a la ausencia de datos en las fuentes oficiales (Tabla 3; Figura 4).

Como era de esperar, el principal proveedor nacional de wolframio continuó siendo la provincia de San Luis y, más concretamente, el complejo Los Cóndores-El Águila, donde SOMINAR había construido una mini-ciudad que llegó a albergar a casi 4.000 habitantes. Dotada de viviendas con luz eléctrica y agua corriente, proveedurías, almacenes, herrerías y sala de enfermería, la flamante localidad llegó a contar con un establecimiento educativo e incluso policía propia, además de hoteles e instalaciones deportivas propias de las grandes ciudades (VARSAVSKY, 2005; DÍAZ, 2017). Como resultado, Los Cóndores-El Águila se erigió en una suerte de enclave minero no muy distinto de los actuales, por completo sujeto a los avatares del mercado mundial.

Si bien los salarios pagados por SOMINAR en Los Cóndores-El Águila eran altos para la época, también lo eran los riesgos laborales asociados a la actividad extractiva. En promedio, cada año fallecían entre cinco y seis mineros debido a los derrumbes ocasionados por las explosiones con dinamita, hecho que la compañía norteamericana procuró ocultar evitando construir un cementerio para así impedir que se conocieran sus tasas de mortalidad ocupacional (VARSAVSKY, 2005).

En 1958, ya en democracia, el gobierno nacional resolvió intervenir nuevamente en el mercado del wolframio, para lo cual sancionó la ley 14.250 y creó un nuevo organismo: el Comité de Comercialización de Minerales (COCOMINE), que liberó a los productores mineros de la obligación de vender su producción a las agencias de rescate pero ratificó el compromiso de éstas de adquirirla en caso de que se le ofreciera (CATALANO, 2004). Sin embargo, una nueva caída de los precios internacionales determinó que en 1962 SOMINAR paralizara definitivamente la explotación de Los Cóndores-El Águila, despidiendo a todos sus trabajadores y generando un masivo éxodo de los pobladores del complejo hacia la cercana localidad de Concarán (VARSAVSKY, 2005). El impacto de esta decisión se hizo sentir rápidamente en el sector, dado que la producción nacional de concentrados de wolframio, que a comienzos de la década rondaba las 700 toneladas anuales, se redujo a poco más de 500 toneladas en 1962 y a menos de 144 toneladas en 1963, disminuyendo así un $87,35 \%$ respecto de los valores máximos de 1957 (1.137 toneladas). Lo mismo puede decirse de las exportaciones: luego de los picos de 1962 (1.975 toneladas) y 1963 (1.042,5 toneladas), cuando SOMINAR remató todos los saldos comerciables de Los Cóndores-El Águila, las remesas al exterior se desplomaron a apenas 4,7 toneladas en 1964.

La paralización de Los Cóndores-El Águila tuvo asimismo otras consecuencias. En 1963, el gobierno nacional dispuso que el sistema de comercialización estatal fuera eliminado por completo, arguyendo que a raíz de la crisis económica, el déficit fiscal y la sistemática caída de las cotizaciones internacionales del wolframio el erario público ya era incapaz de absorber las pérdidas que este sistema le ocasionaba -pagaba 180 pesos por cada kilogramo de wolframio pero lo exportaba a razón de 50-60 pesos (CATALANO, 2004). Si bien es indiscutible que al adquirir la tonelada a 1.299 dólares y venderla a entre 361 y 433 dólares el COCOMINE sufría un fuerte quebranto que rondaba el $70 \%$, no deja de ser sugestivo que el Estado recién reparara en lo inconveniente del negocio luego de que SOMINAR anunciara su decisión de abandonar la mina puntana. Esto sugiere que la regulación del mercado del wolframio respondía a los intereses de esta empresa monopólica y no a los de las pequeñas y medianas firmas de capitales nacionales, quienes supuestamente -según la retórica de los gobiernos de turno- eran los principales destinatarios de las políticas intervencionistas estatales. El impacto conjunto de la parálisis de Los Cóndores-El Águila y la eliminación del COCOMINE implicó que durante el siguiente quinquenio la producción argentina de wolframio oscilara entre 56 y 204

prácticas que durante la Primera y la Segunda Guerra Mundial habían sido justificadas bajo el pretexto de la falta de apoyo estatal, permitiendo que pirquineros independientes trabajaran destructivamente sus propios yacimientos para luego comprarles el mineral y obtener grandes utilidades sin incurrir en riesgo alguno (CATALANO, 1984; LAPIDUS, 2004). 
toneladas anuales (Tabla 3) y que la ocupación en la actividad se derrumbara a sólo 50 puestos de trabajo en todo el país.

Por añadidura, el declive de la minería del wolframio retrasó el desarrollo industrial de la Argentina. Dado que durante los últimos años habían surgido varias fábricas que producían ácido tungstico, wolframio metálico y óxido y carburo de wolframio para varias ramas industriales (siderurgia, defensa, industria automotriz. maquinaria agrícola y pesada, lámparas eléctricas, herramientas de corte, portainsertos y fresas, etc.), el consumo doméstico de wolframio se había duplicado entre 1961 y 1965 , pasando de 50 a 103,5 toneladas anuales (MONROY, 1965). Si bien durante el boom las exportaciones habían limitado el acceso al insumo para estas industrias, la situación empeoró cuando, casi al unísono, el principal productor y el organismo regulador se retiraron del mercado. Como bien señala Catalano (2004), los gobiernos de turno habían malvendido el recurso al exterior a precios no compensatorios sin prever la parálisis que aquejaría al sector cuando la bonanza concluyera; tampoco habían tomado el recaudo de formar una reserva fiscal en beneficio del Estado, ni formulado algún programa de políticas públicas que sostuviera la actividad cuando la coyuntura se agotara. Como resultado, la Argentina se vio afectada por la escasez de wolframio justamente en el momento en que más lo necesitaba para desarrollar su propia industria.

Si bien en 1971 el Estado nacional intentó resucitar a la minería del wolframio, ya era tarde y el destino de la actividad estaba sellado. Los pocos yacimientos que quedaban en pie comenzaron a cerrar escalonadamente en 1973; para 1980 la producción nacional sumaba apenas 78 toneladas, las cuales fueron consumidas en el mercado interno casi en su totalidad. La situación empeoró en 1985 a raíz de un nuevo desplome de las cotizaciones internacionales ocasionado por la saturación del mercado derivada de la sobre-producción soviética, china y coreana. Incapaz de competir con los bajos costos de producción asiáticos, la actividad en Argentina quedó sumida en el más absoluto letargo, limitándose a las recuperaciones de concentrados de antiguas escombreras o relaves sin relevancia estadística (ZOLEZZI, 2004a). Otrora séptimo exportador mundial, la Argentina se convirtió paradójicamente en importador neto de un recurso del cual aún posee reservas, pasando a depender exclusivamente de las compras a Corea del Sur para satisfacer el consumo doméstico.

\section{CONCLUSIONES}

La reconstrucción histórica de la minería del wolframio en la Argentina durante los grandes conflictos bélicos del Siglo XX muestra que esta actividad ocupó un lugar destacado en el país; de hecho, fue el principal rubro productivo y exportable del sector minero metalífero nacional, a tal punto que en el apogeo de la Segunda Guerra Mundial se consagró como el recurso geológico-minero más importante, después de los hidrocarburos. Si bien estuvo muy lejos de liderar la producción mundial, la Argentina siempre se situó entre las primeras diez naciones exportadoras de wolframio debido a las apetencias de Alemania primero y de Estados Unidos después, para quienes controlar las reservas domésticas de este mineral constituyó un objetivo estratégico en su momento. Si, como sugiere Thomàs (2017), el desigual acceso al wolframio por parte de los países beligerantes fue un factor muy importante para el desarrollo y posterior desenlace de estos conflictos militares, entonces el acaparamiento de la producción argentina por la vía de la inversión extranjera y la geopolítica del comercio internacional debe ser considerado como un elemento que tuvo una gravitación no decisiva pero sí complementaria en el resultado global de esas contiendas, contribuyendo a consolidar la hegemonía política y militar de las grandes potencias occidentales.

No menos importante, los sucesivos booms del wolframio acarrearon el despliegue de distintos mecanismos de acumulación por desposesión por parte del capital extranjero. Sin excepciones, la intensa demanda mundial durante las tres coyunturas bélicas trajo aparejados sendos episodios de mercantilización y privatización de la tierra y el subsuelo y acaparamiento neocolonial del recurso, los cuales se desarrollaron al abrigo de la permisiva legislación vigente. El acaparamiento no se limitó apenas al control corporativo de la oferta del recurso, sino que se hizo extensivo a los cauces de comercialización del producto. Lejos del actual esquema de libre comercio y mercados abiertos, el juego de la oferta y la demanda fue suplantado por una estrategia imperialista que, parafraseando a Harvey (2004), promovió dispositivos institucionales externos que hicieron funcionar las asimetrías del intercambio en su propio beneficio, encauzando los flujos comerciales en la dirección deseada. A diferencia de España, donde las naciones beligerantes debieron recurrir al contrabando, el espionaje y el sabotaje para apoderarse del valioso mineral, en Argentina bastó con que las grandes potencias 
explotaran las debilidades estructurales del país vía bloqueos navales, presiones diplomáticas y acuerdos comerciales para que el acceso irrestricto a tal insumo estuviese asegurado.

Esa apropiación neocolonial de recursos del subsuelo fue cuasi-monopólica no sólo desde la perspectiva de los destinos comerciales de la producción, sino también desde el punto de vista corporativo. La alemana HANSA primero y la pléyade de empresas del grupo norteamericano Williams después -con SOMINAR a la cabeza- fueron quienes indiscutiblemente controlaron de principio a fin el circuito de acumulación de la extracción, procesamiento y comercialización del wolframio, explotando la inmensa mayoría de las minas más ricas e importantes de la Argentina. Al igual que en el período actual, la expresión espacial de esa hegemonía fueron las "expropiaciones geográficas" (MACHADO ARÀOZ, 2010), esto es, la producción de economías de enclave (con Los Cóndores-El Águila como ejemplo paradigmático) técnica y políticamente dependientes de las cadenas mundiales de valor del capital transnacional que, una vez que la coyuntura favorable se agota, sufren un irreversible vaciamiento demográfico y funcional.

Otro rasgo que guarda indudables similitudes con las dinámicas expropiatorias contemporáneas se refiere a la anuencia estatal respecto del modelo extractivista. Independientemente de si se trataba de gobiernos liberales, conservadores o populistas, el Estado nacional siempre alentó la entrega del recurso y su explotación por parte del capital extranjero, del mismo modo en que lo han hecho las gestiones neoliberales y neo-desarrollistas de las últimas décadas. Las grandes compañías extranjeras de la época también gozaron de generosas redistribuciones estatales, algunas de ellas similares a las actuales (concesiones y compras de derechos mineros a valores irrisorios, captura de organismos reguladores) y otras que han caído en desuso (venta de minerales al Estado a precios subsidiados en condiciones lesivas para el erario público). Queda claro además que las prácticas fraudulentas, depredatorias e ilegales de las empresas (explotación clandestina de minas no concesionadas, rapiña de yacimientos, transgresiones a la legislación laboral) no son novedosas.

Con respecto a este último punto, el análisis realizado reveló la presencia de formas de explotación de la fuerza de trabajo que se apartaban de la relación salarial "normal" -la tercerización de la extracción y el trabajo infantil- y entraban en flagrante contradicción con las políticas sociales y las conquistas y derechos laborales garantizados por los gobiernos de la época. A esto se le suman cuestiones largamente instaladas (y aún hoy día vigentes) en la minería metalífera argentina, como el fuerte componente extra-regional de la fuerza de trabajo, las riesgosas condiciones de labor y el notable empeño de las compañías del sector por ocultar la mortalidad ocupacional.

En resumidas cuentas, durante las dos guerras mundiales y el conflicto coreano los ciclos de la minería del wolframio se tradujeron al mismo tiempo en una solución espacio-temporal para las grandes potencias occidentales y una miríada de despojos para la Argentina. El wolframio doméstico contribuyó a satisfacer las necesidades del militarismo internacional de la época y resolver las pujas interimperialistas libradas por los países beligerantes, pero a expensas de la extranjerización y expoliación del recurso, la precarización laboral, la profundización de la dependencia política y económica del exterior, el saqueo del erario público y el bloqueo del desarrollo industrial.

\section{REFERENCIAS}

ANGELELLI, V. Yacimientos metalíferos de la República Argentina. Volumen II. La Plata: Comisión de Investigaciones Científicas de la Provincia de Buenos Aires, 1984.

AVELÃS NUNES, J. P. O Estado novo e volfrâmio (1933-1947). Coimbra: Universidade de Coimbra, 2010.

BENINATO, M.; BLASCO, J. C. San Luis. In: SEGEMAR (Ed.) Historia de la minería argentina. Tomo 2. Buenos Aires: Servicio Geológico Minero Argentino, 2004. p. 217-224.

CARMONA BADÍA, X. La minería española del wolframio, 1936-1954: los años de la fiebre. In: SÁNCHEZ RECIO, G.; TASCÓN FERNÁNDEZ, J. (Ed.) Los empresarios de Franco. Política y economía en España 1936-1957. Barcelona: Crítica-PUA, 2003. p. 261-280.

CARUANA DE LAS CAGIGAS, L.; GONZÁLEZ CALLEJA, E. La producción y contrabando de wolframio en España durante la Primera Guerra Mundial. Ayer, n. 95, v. 3, p. 183-209, 2014. 
CARUANA DE LAS CAGIGAS, L.; ROCKOFF, H. A wolfram in sheep's clothing: economic warfare in Spain, 1940-1944. The Journal of Economic History, v. 63, n. 1, p. 65-99, 2003. https://doi.org/10.1017/S0022050703001748

CATALANO, E. Breve historia minera de la Argentina. Buenos Aires: Depalma, 1984.

Antecedentes y estructura histórica de la minería argentina. In: SEGEMAR (Ed.). Historia de la minería argentina. Tomo 1. Buenos Aires: Servicio Geológico Minero Argentino, 2004. p. 1-176.

CORIGLIANO, F. La neutralidad acosada (1939-1945). La Argentina frente a la Segunda Guerra Mundial. Todo es Historia, n. 506, p. 54-76, 2009.

CUVI, N. "Dejen que el diablo haga lo demás": la promoción de productos complementarios en América Latina durante la década de 1940. Historia Crítica, n. 44, p. 158-181, 2011. https://doi.org/10.7440/histcrit44.2011.08

DÍAZ, J. Mina Los Cóndores: camino a la oscuridad (I). San Luis: El Diario de la República, 2017. Disponible en: https://www.eldiariodelarepublica.com/sanluis-sugente/Mina-Los-Condores-camino-ala-oscuridad-20170213-0028.html. Acceso en: 8 ag. 2019.

DGMGyH. Memoria de la División General de Minas, Geología e Hidrología correspondiente al año 1909. Buenos Aires: Dirección General de Minas, Geología e Hidrología, 1911.

DGMGyH. Estadística minera de la Nación. Año 1919. Buenos Aires: Dirección General de Minas, Geología e Hidrología, 1925.

DGMGyH. Estadística minera de la Nación. Año 1924. Buenos Aires: Dirección General de Minas, Geología e Hidrología, 1929.

DGMGyH. Estadística minera de la Nación. Año 1929. Buenos Aires: Dirección General de Minas, Geología e Hidrología, 1930.

DMyG. Estadística minera de la Nación. Año 1934. Buenos Aires: Dirección de Minas y Geología, 1935.

DMyG. Estadística minera de la Nación. Año 1939. Buenos Aires: Dirección de Minas y Geología, 1940.

DMyG. Estadística minera de la Nación. Año 1943. Buenos Aires: Dirección de Minas y Geología, 1946.

DMyG. Estadística minera de la Nación. Año 1944. Buenos Aires: Dirección de Minas y Geología, 1948.

DNM. Estadística minera de la Nación. Años 1945-1949. Buenos Aires: Dirección Nacional de Minería, 1953.

GÓMEZ LENDE, S. Acumulación por desposesión y conflictos espaciales. La minería metalífera en la Argentina contemporánea. Saarbrücken: Editorial Académica Española, 2015.

GÓMEZ LENDE, S. Mega-minería metalífera y acumulación por desposesión en Argentina. Categorías de análisis y ejemplos empíricos. RevIISE - Revista de Ciencias Sociales y Humanas, $\mathrm{n}$. 10, p. 177-199, 2017.

HARVEY, D. Los límites del capitalismo y la teoría marxista. Buenos Aires: FCE, 1990.

HARVEY, D. El nuevo imperialismo. Madrid: Akal, 2004.

HARVEY, D. Breve historia del neoliberalismo. Madrid: Akal, 2007.

HARVEY, D. Diecisiete contradicciones y el fin del capitalismo. Quito: IAEN, 2014.

KABAT, M. El peronismo y la oposición ante la Guerra de Corea. X Jornadas De Sociología De La UNLP. La Plata: Universidad Nacional de La Plata, 2018.

LAPIDUS, A. Política minera. Período 1950-1984. In: SEGEMAR (Ed.) Historia de la minería argentina. Tomo 1. Buenos Aires: Servicio Geológico Minero Argentino, 2004. p. 239-242.

LUXEMBURGO, R. La acumulación del capital. México, D. F.: Fondo de Cultura Económica, 1967. 
MACHADO ARÁOZ, H. "El agua vale más que el oro". Grito de resistencia decolonial contra los nuevos dispositivos expropiatorios. In: DELGADO RAMOS, G (Ed.) Ecología política de la minería en América Latina. Aspectos socioeconómicos, legales y ambientales de la minería. México: UNAM, 2010. p. 59-96.

MACHADO ARÁOZ, H. Potosí, el origen. Genealogía de la minería contemporánea. Buenos Aires: Mardulce, 2014.

MANDEL, E. Tratado de economía marxista. Tomo II. México: FCE, 1969.

MARX, K. El capital. Crítica de la economía política. Tomo I. México, D. F.: FCE, 1968.

MONROY, $\mathrm{H}$. Mercado local de minerales de tungsteno. Consumo actual y su proyección hasta 1969. Buenos Aires: Secretaría de Estado de Industria y Minería, 1965.

RAYES, A. Los destinos de las exportaciones y la neutralidad argentina durante la Primera Guerra Mundial. Política y Cultura, n. 42, p. 31-52, 2014.

ROUGIER, M. Hacia una nueva política industrial. Los proyectos de producción de metales no ferrosos en la Argentina durante la Segunda Guerra Mundial. Revista de Historia Industrial, n. 50, p. 73-111, 2012.

SElyM. Estadística minera de la Nación. Años 1957-1961. Buenos Aires: Secretaría de Estado de Industria y Minería, 1965.

SEEyM. Estadística minera de la Nación. Años 1960-1965. Buenos Aires: Secretaría de Estado de Energía y Minería, 1968a.

SEEyM. Estadística minera de la Nación. Año 1966. Buenos Aires: Secretaría de Estado de Energía y Minería, 1968b.

SEEyM. Estadística minera de la Nación. Año 1967. Buenos Aires: Ministerio Secretaría de Estado de Energía y Minería, 1968c.

SGROSSO, P. Wolfram - Se proponen medios y soluciones al problema de la baja del precio. Buenos Aires: Dirección General de Minas, Geología e Hidrología, 1945.

SM. Estadística minera de la Nación. Años 1950-1952. Buenos Aires: Subsecretaría de Minería, 1958a.

SM. Estadística minera de la Nación. Años 1953-1954-1955-1956. Buenos Aires: Subsecretaría de Minería, 1958b.

THOMÀS, J. M. Tungsten in the Second World War: China, Japan, Germany, the Allies and Iberia. Comillas Journal of International Relations, n. 10, p. 65-90, 2017. https://doi.org/10.14422/cir.i10.y2017.005

VARSAVSKY, J. San Luis: la mina Los Cóndores. Buenos Aires: Diario Página 12, 2005. Disponible en: https://www.pagina12.com.ar/diario/suplementos/turismo/9-644-2005-07-20.html. Acceso en: 8 ag. 2019.

ZOLEZZI, R. E. Wolframio. In: SEGEMAR (Ed.). Historia de la minería argentina. Tomo 2. Buenos Aires: Servicio Geológico Minero Argentino, 2004a. p. 339-350.

Córdoba. In: SEGEMAR (Ed.). Historia de la minería argentina. Tomo 2. Buenos Aires: Servicio Geológico Minero Argentino, 2004b. p. 103-130.

Recebido em: 21/02/2020

Aceito para publicação em: 30/12/2020 